Universidade de São Paulo

Escola de Enfermagem

Maíra Shiramizu da Silva

QUALIDADE DE VIDA RELACIONADA À SAÚDE DE PACIENTES COM

DOENÇA PULMONAR OBSTRUTIVA CRÔNICA

São Paulo

2011 
Maíra Shiramizu da Silva

\section{QUALIDADE DE VIDA RELACIONADA À SAÚDE DE PACIENTES COM DOENÇA PULMONAR OBSTRUTIVA CRÔNICA}

Dissertação de Mestrado apresentada ao Programa de Pós-Graduação em Enfermagem na Saúde do Adulto PROESA, da Escola de Enfermagem da Universidade de São Paulo, para obtenção do título de Mestre em Enfermagem.

Área de Concentração: Enfermagem na Saúde do Adulto.

Orientadora: Prof ${ }^{a}$. Dra . Miako Kimura

São Paulo 


\section{FOLHA DE APROVAÇÃO}

Nome: Maíra Shiramizu da Silva

Título: Qualidade de vida relacionada à saúde de pacientes com doença pulmonar obstrutiva crônica

Dissertação de Mestrado apresentada ao Programa de Pós-Graduação em Enfermagem na Saúde do Adulto PROESA, da Escola de Enfermagem da Universidade de São Paulo, para obtenção do título de Mestre em Enfermagem.

Área de Concentração: Enfermagem na Saúde do Adulto.

Orientadora: Profa ${ }^{a}$ Dra . Miako Kimura

Aprovado em

BANCA EXAMINADORA

Prof. Dr. Instituição

Julgamento Assinatura

Prof. Dr. Instituição

Julgamento Assinatura

Prof. Dr. Instituição

Julgamento Assinatura 


\section{DEDICATÓRIA}

Aos meus pais, Luiza Yooko Shiramizu da Silva e Gilson Gomes da Silva, pelo incentivo, torcida e por fazerem dos meus sonhos, os seus.

Aos meus irmãos Isa e Gil, pelo companheirismo e pelas palavras carinhosas a cada realização minha.

À minha avó さとみ 白水 pelo exemplo de vida e inspiração,

ao meu avô ただし 白水, por quem eu me motivo a estudar a DPOC e

aos parentes e amigos que vibram com cada conquista minha e me impulsionam para a próxima. 


\section{AGRADECIMENTOS}

À minha orientadora professora dra Miako Kimura, a quem eu carinhosamente chamo de sensei Miako. "Sensei", do japonês, é um título utilizado para referenciar uma pessoa que atingiu nível de maestria em suas atividades; mais do que isso, para mim, a sensei é um exemplo de competência, perseverança, uma pessoa que desempenha como ninguém seu trabalho e sente orgulho de ser enfermeira, pesquisadora, professora e mentora de todos nós. Muito obrigada!

Ao professor dr. Rafael Stelmach, pela recepção calorosa, pela prontidão em nos ajudar e abrir portas para que nossa pesquisa fosse possível.

À Professora dra. Vera Lúcia Conceição de Golveia Santos pelos apontamentos assertivos, críticas construtivas, pelos debates e interesse pelo estudo.

Ao Ricardo Luís Barbosa, pela análise estatística minuciosa e por seus ensinamentos.

Ao Dr. Frederico Leon Arrabal Fernandes, pela dedicação e incentivo constante ao estudo da Pneumologia.

À equipe do Ambulatório de Pneumologia do HCFMUSP que me recebeu carinhosamente, me auxiliou em meus questionamentos, me deu abertura para fazer parte dessa equipe e me auxiliou a compreender melhor os pacientes com DPOC. 
Ao mutirão da solidariedade "todos por um mestrado" que tornou menos árdua a conclusão dessa dissertação: Fernanda Thaís Nogueira, Glauco Nepomuceno, Marília Maciel, Gil Shiramizu, Maria Cícera, Luiza Yooko e Gilson Gomes. 
"Torne o impossível, possível

$$
\begin{aligned}
& \text { o possível, fácil } \\
& \text { e o fácil, elegante” }
\end{aligned}
$$

Moshe Feldenkraiss 
Silva MS. Qualidade de vida relacionada à saúde de pacientes com doença pulmonar obstrutiva crônica [dissertação]. São Paulo: Escola de Enfermagem, Universidade de São Paulo; 2011.

\section{RESUMO}

Introdução: Medidas baseadas no relato dos pacientes vêm sendo incorporadas de forma crescente como parâmetros adicionais na avaliação das intervenções e na decisão por modalidades de tratamento. Um dessas medidas é a avaliação da Qualidade de Vida Relacionada à Saúde (QVRS). Nos diversos estudos de QVRS em DPOC constata-se a predominância daqueles que avaliaram a influência de fatores clínicos relacionados à função pulmonar. Objetivos: Avaliar a QVRS de pacientes com DPOC e analisar a influência de fatores clínicos e sóciodemográficos e de bem-estar espiritual, na QVRS desses pacientes. Método: Foram entrevistados 70 pacientes atendidos em um ambulatório de pneumologia. Os dados foram coletados utilizando-se três instrumentos: uma ficha de caracterização dos pacientes, a Escala de Bem Estar Espiritual (EBE), contendo um componente religioso (BER) e um existencial (BEE), e o Saint George Respiratory Questionnaire (SGRQ), composto pelos domínios Sintomas, Atividades e Impactos. A regressão linear múltipla, método backward, foi a estratégia utilizada para identificação dos fatores associados à QVRS.

Resultados: Os pacientes eram homens, em sua maioria, tinham em média 64,24 anos ( $\mathrm{dp}=10,22$ ), baixo nível de escolaridade e de renda, católicos, exfumantes, com alta carga tabágica e com DPOC grave ou muito grave. Os escores do SGRQ indicaram má QVRS, principalmente em função das limitações na atividade física (média de $72 \%, d p=15$ ). No domínio Sintomas, a média foi de $65 \%(d p=18)$, de $57 \%(d p=19)$ no domínio Impactos e de $63 \%$ $(d p=15)$ no escore total. A EBE mostrou um alto nível de bem-estar espiritual, com maior contribuição do componente religioso, o escore total foi de 94,87 $(d p=13,56), 51,50(d p=8,68)$ para o domínio religioso e 43,37 $(d p=6,76)$ para o existencial. Nas analises multivariadas, as variáveis de maior influência na QVRS foram: a escolaridade, presente nos modelos finais dos três domínios e no total do SGRQ (valores de $\beta-15,15$ em sintomas, $\beta-10,75$ em atividade, $\beta$ 19,33 em impactos e $\beta-44,20$ no escore total) ; presença de comorbidades ( $\beta$ $9,00)$, trabalho atual $(\beta-12,22)$, BER $(\beta 0,41)$ e $\operatorname{BEE}(\beta-0,88)$ no domínio Atividade; tempo de DPOC $(\beta 0,61)$, no domínio Sintomas e carga tabágica $(\beta$ $0,131)$ no domínio Impactos, para o escore total, trabalho atual $(\beta-36,59)$, presença de comorbidades $(\beta-17,88)$, $\operatorname{BER}(\beta$ 1,30) e $\operatorname{BEE}(\beta-1,94)$. Conclusão: Os resultados deste estudo reforçam a importância de considerar fatores como a escolaridade, o trabalho, a presença de comorbidades, a religiosidade e a espiritualidade na assistência integral aos pacientes com DPOC, visando proporcionar-lhes uma melhor qualidade de vida.

Descritores: Qualidade de vida. Saúde. Espiritualidade. Doença pulmonar obstrutiva crônica. 
Silva MS. Health related quality of life in patients with chronic obstructive pulmonar disease. São Paulo: Escola de Enfermagem, Universidade de São Paulo; 2011.

\section{ABSTRACT}

Introduction: Patient Report Outcomes are being increasingly incorporated as additional parameters in the evaluation of interventions and decision for treatment modalities. One of these measures is the evaluation of Health Related Quality of Life (HRQOL). In several studies of HRQOL in COPD patients there is a predominance of evaluating the influence of clinical factors related to lung function.

Objectives: This study aimed to evaluate the HRQOL of COPD patients and analyze the influence of sociodemographic, clinical and spiritual well being factors, on patients HRQOL.

Method: We interviewed 70 patients treated on a pulmonology outpatient. Data were collected using three instruments: a form of patients characterization, the Saint George Respiratory Questionnaire (SGRQ), comprising Symptoms, Activities and Impacts domains, and Spiritual Well-Being Scale (SWBS), which includes a religious component (RWB) and an existential (EWB). Multiple linear regression, backward method, was the strategy chose to identify associated factors with HRQOL.

Results: The patients were majority men, had an average of 64.24 years (SD $=$ 10.22), low education and income, Catholics, former smokers, with high smoking load and severe or very severe COPD. The SGRQ scores indicated poor HRQOL, mainly due to limitations in physical activity (average of $72 \%$, sd = $15)$. In the Symptoms domain the average was $65 \%(s d=18), 57 \%(s d=19)$ in the Impacts domain and of $63 \%(s d=15)$ in the total score. The SWBS showed a high level of spiritual well-being (total score of 94.87 , $\mathrm{sd}=13.56$ ), with major contribution of religious component, the $51.50(\mathrm{sd}=8.68)$ for the religious domain and 43.37 ( $\mathrm{sd}=6.76$ ) to the existential one. In multivariate analysis, the variables that influenced HRQOL were: schooling, present in the final model of the three domains and SGRQ total (values of $\beta-15.15$ in Symptoms, $\beta-10.75$ in Activities, $\beta-19$ in Impacts, and $\beta-44.20$ in total score); comorbidities presence $(\beta-9.00)$, current job $(\beta-12.22)$, RWB $(\beta$ 0.41) and EWB $(\beta-0,88)$ in Activities area; duration of COPD $(\beta$ 0.61) in Symptoms; tobacco intake $(\beta$ $0.131)$ in Impacts and current job $(\beta-36.59)$, comorbidities presence $(-17.88$ $\beta)$, RWB ( $\beta$ 1.30) and EWB ( $\beta-1.94)$ in total score. Conclusion: The results of this study reinforce the importance of considering factors such as education, employment, presence of comorbidities, religion and spirituality in comprehensive care to patients with COPD in order to provide them a better quality of life.

Keywords: Quality of life. Health. Spirituality. chronic obstructive pulmonary disease. 


\section{LISTA DE TABELAS}

Tabela 01 - Caracterização sóciodemográfica e clínica

dos pacientes com DPOC. São Paulo, 2008.

Tabela 02 - Coeficiente $\alpha$ de Cronbach dos itens e domínios

Saint George Respiratory Questionnaire e Escala de Bem Estar Espiritual. São Paulo, 2008.

Tabela 03 - Estatística descritiva dos escores do Saint

George Respiratory Questionnaire e da

Escala de Bem Estar Espiritual. São Paulo, 2008.

Tabela 04 - Frequência de pacientes nas categorias de resposta aos itens do domínio sintomas do questionário Saint George Respiratory Questionnaire. São Paulo 2008.

Tabela 05 - Frequência de pacientes nas categorias de resposta aos itens do domínio atividade do questionário Saint George Respiratory Questionnaire, São Paulo 2008.

Tabela 06 - Frequência de pacientes nas categorias de resposta aos itens do domínio impactos do questionário Saint George Respiratory Questionnaire, São Paulo 2008.

Tabela 07 - Regressão linear múltipla para o domínio sintomas do Saint George Respiratory Questionnaire. São Paulo, 2008. 48

Tabela 08 - Regressão linear múltipla para o domínio Atividade do Saint George Respiratory Questionnaire. São Paulo, 2008. 50

Tabela 09 - Regressão linear múltipla para o domínio Impactos do Saint George Respiratory Questionnaire. São Paulo, 2008. 
Tabela 10 - Regressão linear múltipla para o escore total do Saint George Respiratory Questionnaire. São Paulo, 2008. 


\section{SIGLAS}

AQ20 - Questionário de vias aéreas 20

BEE - Bem Estar Existencial

BEEt - Bem Estar Espiritual Total

BER - Bem Estar Religioso

BODE - índice de massa corporal, obstrução das vias aéreas, dispnéia e capacidade ao exercício

COPD - Chronic Obstructive Pulmonary Disease

CCQ - Clinical Chronic Obstructive Pulmonary Disease Questionnaire

$\mathrm{CRQ}$ - Chronic Respiratory Questionnaire

DPOC - Doença Pulmonar Obstrutiva Crônica

EBE - Escala de Bem Estar Espiritual

EPIDEPOC - Estudo Epidemiológico, observacional e descritivo

EQ-5D - EuroQol 5 Dimensions

EVOCA - EVOlucion de la CAlidad de vida em los pacientes con epoc

FACIT - Functional Assessment of Chronic Illness Therapy

FLOW - Function, living, outcomes and work study

GOLD - Global initiative for chronic Obstructive Lung Disease

HADS - The Hospital Anxiety And Depression Scale

HAS - Hipertensão Arterial Sistêmica

HRQL - Health Related Quality of Life

IMC - Índice de Massa Corpórea

ISOLDE - Inhaled Steroids in Obstruction Lung Disease in Europe

NETT - the National Emphysema Treatment Trial 
OMS - Organização Mundial da Saúde

PaCO2 - Pressão parcial de dióxido de carbono

PaO2 - Pressão parcial de oxigênio

PEmáx - Pressão Expiratória máxima

PImáx - Pressão Inspiratória máxima

PLATINO - Proyeto LATinoamericano de INvestigacion em Obstruccion pulomonar

QV - Qualidade de Vida

QVRS - Qualidade de Vida Relacionada à Saúde

QWB - Quality of Well Being

SF-12 - Short Form-12 versão do Medical Outcomes Study

SF-36 - Short Form-36 versão do Medical Outcomes Study

SGRQ - Saint George Respiratory Questionnaire

SOLDQ - Seattle Obstructive Lung Disease Questionnaire

SpO2 - Saturação periférica de oxigênio

SPSS - Statistical Package for the Social Sciences

TC6 - Teste de Caminhada de 6 minutos

VEF1 - Volume Expiratório Forçado no $1^{\circ}$ segundo

VEF1/CVF - Relação entre o volume expiratório forçado no primeiro minuto e a capacidade vital forçada

VO2max - Medida do consumo máximo de oxigênio

VO2pico - Medida do mais alto consumo de O2 medido durante um teste de intensidade progressiva

WHOQOL - the World Health Organization Quality Of Life assessment instrument 


\section{SUMÁRIO}

1 APRESENTAÇÃO 15

2 INTRODUÇÃO 16

3 REFERENCIAL TEÓRICO

3.1 Qualidade de vida e Qualidade de Vida Relacionada à Saúde 20

3.2 Qualidade de Vida Relacionada à Saúde em DPOC e

$\begin{array}{ll}\text { fatores associados } & 22\end{array}$

$\begin{array}{ll}4 \text { OBJETIVOS } & 30\end{array}$

5 MÉTODOS

$\begin{array}{ll}5.1 \text { Tipo de estudo } & 31\end{array}$

5.2 Local de estudo 31

5.3 Amostra 32

5.4 Procedimentos para coleta de dados 32

5.5 Instrumentos de coleta de dados 33

5.6 Descrição das variáveis do estudo 36

5.7 Análise dos dados e tratamento estatístico 37

6 RESULTADOS

6.1 Caracterização sóciodemográfica e clínica dos pacientes

6.2 Análise da consistência interna do Saint George

Respiratory Questionnaire e da Escala de Bem Estar

Espiritual

6.3 Avaliação da Qualidade de Vida Relacionada à Saúde 
6.3.1 Estatística descritiva do SGRQ e EBE

6.3.2 Frequência de respostas aos itens dos

domínios do SGRQ

6.4 Análise de regressão linear múltipla

7 DISCUSSÃO

7.1 Frequência de respostas dos itens do instrumento

de QVRS

7.2 Avaliação da QVRS

8 CONCLUSÕES

9 LIMITAÇÕES

10 REFERÊNCIAS

11 APÊNDICES

11.1 Apêndice A

11.2 Apêndice $B$

12 ANEXOS

12.1 Anexo 01

12.2 Anexo 02

12.3 Anexo 03 80

12.4 Anexo 04

12.5 Anexo 05

12.6 Anexo 06 


\section{APRESENTAÇÃO}

Meu interesse pelo estudo e cuidado de pacientes com Doença Pulmonar Obstrutiva Crônica (DPOC) surgiu no segundo ano da graduação em enfermagem, em uma aula ministrada pela professora Dra. Miako Kimura. Minha curiosidade pelo assunto aliada ao incentivo e encorajamento que recebi da professora Miako na área de pesquisa, fez com que nos tornássemos parceiras desde a iniciação científica até o mestrado.

A DPOC é uma enfermidade para a qual se desconhece a "cura"; por isso, o que se busca é promover e manter a melhor qualidade de vida possível, por meio de intervenções terapêuticas que garantam o bem do paciente e evitem ou desacelerem a progressão da doença e dos sintomas.

Hoje faço parte da equipe de profissionais do Pronto Socorro do Hospital das Clínicas. A atuação em um serviço de emergência, que recebe pacientes com DPOC em crise, me fez enxergar como é de fundamental importância o entendimento da doença, o tratamento precoce e assertivo, e a prevenção de exacerbações.

Durante a convivência com os pacientes no ambulatório, ouvir o relato deles sobre sua nova condição de vida, os anseios, as dificuldades, os medos, as expectativas, me fizeram ver que existe uma gama de fatores que interferem no tratamento e consequentemente no seu sucesso e, que, nós profissionais de saúde e pesquisadores devemos nos atentar a eles.

Acredito que eu como enfermeira, e a enfermagem em pneumologia, ainda precisamos superar inúmeros desafios para prestar um cuidado de qualidade e diferenciado a esses pacientes. Existem muitas lacunas no conhecimento da DPOC que precisam ser preenchidas; minha motivação de contribuir minimamente para isso me levou à realização deste estudo. 


\section{INTRODUÇÃO}

De acordo com a Organização Mundial da Saúde, mais de 80 milhões de pessoas no mundo convivem com a Doença Pulmonar Obstrutiva Crônica (DPOC) e cerca de 3 milhões de pessoas morreram em decorrência da doença, em 2005. A DPOC é uma das maiores causas de morte e um enorme e crescente problema, não apenas médico, mas também social e econômico (Voll-Aanerud et al., 2008).

Dados do Proyeto Latinoamericano de Investigación en Obstrucción Pulmonar (PLATINO), um estudo multicêntrico envolvendo cinco cidades da América Latina, mostraram que, em 2003, a DPOC acometia 15,8\% da população acima de 40 anos na região metropolitana de São Paulo. Essa prevalência pode ser considerada elevada, quando se atenta para o fato de que, em grande parte dos casos, a doença é prevenível (Menezes et al., 2005).

A DPOC, que inclui o enfisema e a bronquite crônica, pode ser caracterizada como um estado patológico onde há limitação no fluxo de ar, que não é completamente reversível. Essa limitação é comumente progressiva e associada a uma resposta inflamatória pulmonar anormal a gases e partículas tóxicas. Os fatores de risco associados à DPOC podem ser tanto ambientais e comportamentais, quanto de susceptibilidade do indivíduo e, normalmente, a doença surge da interação entre esses fatores (GOLD, 2007). A resposta inflamatória ligada à DPOC tem sido atribuída à participação de linfócitos T CD8+, macrófagos e neutrófilos, assim como de um grande número de quemocinas, citocinas e proteinases que, tanto contribuem para o remodelamento do tecido pulmonar, levando à limitação irreversível do fluxo aéreo, característico da doença, como para as comorbidades frequentemente observadas nos pacientes (Rennard, 2007).

O desenvolvimento de sintomas na DPOC é insidioso e, geralmente, ocorre em um longo período de tempo. Enquanto o envelhecimento fisiológico normal leva a um decréscimo do volume expiratório forçado no primeiro segundo (VEF1) de $30 \mathrm{ml}$ por ano, pessoas com DPOC podem perder mais de 
$80 \mathrm{ml}$ ao ano. A limitação funcional leva a sinais e sintomas, que começam a se manifestar quando a perda de função pulmonar atinge níveis de 50 a $70 \%$. À medida que a DPOC progride, a mecânica pulmonar é alterada, aumentando o esforço expiratório de 10 a 20 vezes em relação a um indivíduo saudável (Bauldoff, Diaz, 2006).

Em pacientes com enfisema, o septo alveolar é destruído e ocorre um aumento dos espaços aéreos. O mecanismo de destruição ainda não foi completamente estabelecido, mas o cigarro é apontado como uma grande fonte de agentes inflamatórios; já em pacientes com bronquite crônica, ocorre uma exposição prolongada a agentes irritantes, tais como a fumaça do cigarro, que levam a uma hipersecreção de muco e hiperplasia e hipertrofia das estruturas da via aérea, resultando em diminuição da luz da via aérea e consequente diminuição da eliminação do muco. Como em ambos os casos (enfisema e bronquite crônica), o cigarro pode ser o agente causador, muitos pacientes apresentam alterações patológicas das duas doenças (Bauldoff, Diaz, 2006).

A patogenia e as manifestações clínicas da DPOC não são confinadas somente à inflamação pulmonar e ao remodelamento estrutural, mas se estendem a uma enorme variedade de alterações sistêmicas. Os efeitos extra pulmonares incluem inflamação sistêmica, anormalidades nutricionais e perda de peso, disfunção da musculatura esquelética e outros efeitos em órgãos e sistemas. A maior carga da DPOC resulta nos sintomas respiratórios, como, por exemplo, a falta de ar, a tosse crônica e as exacerbações, que, frequentemente, requerem hospitalização(Decramer et al., 2005).

À medida que a função pulmonar piora, as exacerbações $s$ da doença ocorrem com maior frequência. Para indivíduos com DPOC, as exacerbações são um indicador de uma fase de maior gravidade e limitação; uma fase pontuada pela necessidade de medicações de alto custo, aumento na frequência de consultas ambulatoriais, pronto atendimento e internações, e, sobretudo, um aumento no risco de morte. Mas, talvez mais importante, as exacerbações da DPOC anunciam um declínio da qualidade de vida, no qual vidas tornam-se mais definidas por limitações que por possibilidades (Koff et al., 2009). 
É importante enfatizar que a pessoa com diagnóstico de DPOC deve, necessariamente, modificar seus hábitos e o estilo de vida. $\mathrm{O}$ uso de fumo, do álcool, o contato com poluentes e com fumantes, entre outros, deverão ser restritos ou abandonados. Além disso, a pessoa deverá buscar trabalho compatível, novas formas de lazer e reajustar-se financeiramente (Kerkoski et al., 2007).

Todo esse conjunto de alterações faz com que os indivíduos com DPOC percebam-se menos satisfeitos com suas vidas, menos capazes de desempenhar atividades da vida diária e com uma pior condição física, social e emocional em relação àqueles com outras doenças crônicas (Hu, Meek, 2005).

Infelizmente, exceto pela suplementação de oxigênio, a maioria dos tratamentos não tem demonstrado uma melhora na sobrevida. Da mesma maneira, nenhuma intervenção, exceto a cessação do fumo, tem se mostrado efetiva para deter a taxa de declínio da função pulmonar. Dessa forma, a maioria dos tratamentos e intervenções tem foco no alívio dos sintomas, no aumento da tolerância ao exercício físico, na prevenção e tratamento das exacerbações (Tomas, Varkey, 2004; Voll-Aanerud et al., 2008).

$O$ aumento da sobrevida e o declínio dos parâmetros de função pulmonar são medidas tradicionalmente utilizadas na avaliação dos efeitos da DPOC e dos seus tratamentos. Embora sejam reconhecidamente importantes tanto para os profissionais como para os pacientes, essas medidas não são capazes de representar a complexa gama de repercussões da doença e dos tratamentos nos diversos aspectos da vida dos pacientes (Curtis, Patrick, 2003).

Reconhecendo as limitações de centrar o foco apenas nesses resultados e entendendo que a DPOC afeta múltiplos aspectos da vida dos pacientes, muitos clínicos e pesquisadores vêm incorporando medidas de qualidade de vida, como um parâmetro adicional na avaliação das intervenções e na decisão por modalidades de tratamento (Tomas, Varkey, 2004).

Entre as diversas medidas usadas no acompanhamento de pacientes com DPOC, a literatura tem destacado a importância das medidas centradas no relato dos próprios pacientes, tais como a Qualidade de Vida Relacionada à Saúde (QVRS), uma vez que elas refletem mais acuradamente os efeitos da 
doença e do tratamento na vida diária dos pacientes (Haughney, GruffyddJones, 2004).

A obtenção de dados sobre a QVRS permite agregar as informações relatadas pelos próprios pacientes àquelas baseadas na perspectiva do clínico ou em medidas fisiológicas. Isto é importante, uma vez que a melhoria de medidas clínicas de uma determinada doença, não necessariamente reflete uma melhora na condição de saúde percebida pelo paciente.

$\mathrm{Na}$ assistência a pessoas com doenças crônicas, como a DPOC, a avaliação da qualidade de vida e dos seus fatores determinantes podem trazer contribuições relevantes para a definição de prioridades assistenciais, bem como acompanhar a evolução da doença e do tratamento, identificar precocemente condições de morbidade e melhorar o relacionamento da equipe de saúde com a pessoa doente (Pimentel, 2006).

Como fundamentação teórica, o capítulo seguinte apresenta um panorama geral sobre os conceitos e medidas de qualidade de vida e qualidade de vida relacionada à saúde. A seguir, é apresentada uma seleção de artigos que tratam dos fatores associados à qualidade de vida em DPOC. 


\section{REFERENCIAL TEÓRICO}

\subsection{QUALIDADE DE VIDA E QUALIDADE DE VIDA RELACIONADA À SAÚDE}

A expressão qualidade de vida $(Q V)$, originalmente proposta por economistas e sociólogos, passou a ser objeto de interesse científico nas mais diversas áreas do conhecimento a partir da década de 1970, ocorrendo, desde então, um acentuado crescimento de publicações sobre o tema (Evans, 1994).

No campo da saúde, um dos incentivos à utilização desse conceito é atribuído à Food and Drug Administration, que desde 1985, vem incluindo desfechos subjetivos, como os relatos dos pacientes sobre qualidade de vida relacionada à saúde (QVRS), entre as medidas de resultado de ensaios clínicos para aprovação de novas drogas e intervenções de saúde (Vogelsang, Brahmer, 2002). Destaca-se, também, a contribuição da Organização Mundial da Saúde (OMS). Ao definir saúde como "um estado de completo bem-estar físico, mental e social, e não apenas a ausência de doença ou enfermidade", a OMS incorporou, explicitamente, nesta definição, a noção subjetiva de bemestar nas diferentes dimensões da vida e a relevância de fatores não fisiológicos para a saúde, aspectos estes valorizados nas concepções de qualidade de vida (King, Hinds, 1998).

O termo qualidade de vida tem recebido diferentes denominações na literatura médica. Em revisão de literatura, Gill, Feinstein (1994) observaram que estado de saúde, estado funcional e qualidade de vida são conceitos que têm sido frequentemente utilizados como sinônimos. Para estes autores, no entanto, o conceito de qualidade de vida é muito mais amplo do que o estado de saúde, devendo incluir, além dele, aspectos não-médicos, como trabalho, família, amigos e outras circunstâncias da vida.

Essa perspectiva ampliada de QV está refletida na estrutura dos instrumentos da OMS, World Health Organization Quality of Life Instrument (WHOQOL-100 e WHOQOL-bref). No primeiro, a QV é avaliada em relação a 
seis domínios: físico, psicológico, nível de independência, relações sociais, meio ambiente e espiritualidade/ religião/ crenças pessoais e, na versão abreviada, por quatro destes domínios: físico, psicológico, relações sociais e meio ambiente (Fleck, et al., 1999; Fleck et al., 2000).

Esses instrumentos foram desenvolvidos numa perspectiva transcultural pelo grupo WHOQOL, com base na concepção de que qualidade de vida representa "a percepção do indivíduo de sua posição na vida, no contexto da cultura e sistema de valores nos quais ele vive e em relação aos seus objetivos, expectativas, padrões e preocupações (Fleck et al., 1999; Pimentel, 2006).

Já o conceito de Qualidade de Vida Relacionada à Saúde (QVRS) é utilizado de forma mais específica, para referir-se à percepção subjetiva dos aspectos da vida que são diretamente influenciados pelas alterações no estado de saúde ou que são afetados pela doença e pelo tratamento (Testa; Simonson, 1996). A QVRS refere-se à capacidade de superar as dificuldades resultantes de condições mórbidas ou de viver sem doenças (Minayo, Hartz, Buss, 2000). O conceito incorpora também diversos aspectos, entre eles: os sintomas, a função física, a capacidade cognitiva, a condição psicossocial e emocional e a adaptação à doença (Tomas, Varkey, 2004).

$\mathrm{Na}$ área respiratória, a definição de QVRS proposta por Paul Jones, em 1991, é uma das mais citadas (Camelier, 2004) e é expressa como "a quantificação do impacto da doença nas atividades de vida diária e no bem estar do paciente, de maneira formal e padronizada". Por esta definição, inferese a importância das medidas de QVRS, uma vez que, por meio delas, é possível quantificar percepções subjetivas sobre o impacto global da doença na vida dos indivíduos, transformando-as em dados mensuráveis e passíveis de análise objetiva (Camelier, 2004).

Para serem adequados a esse propósito, é importante que os instrumentos de medida de QVRS sejam fundamentados em bases teóricas e empíricas que orientem os procedimentos de mensuração e interpretação dos achados e que apresentem atributos que assegurem a precisão da medida (confiabilidade) e a representação do conceito que pretendem medir (validade). Os instrumentos devem ainda demonstrar responsividade, ou seja, a capacidade de detectar 
mudanças ao longo do tempo ou relacionadas a intervenções (Scientific Advisory Committee of the Medical Outcomes Trust, 2002).

Diversos questionários de qualidade de vida, genéricos e específicos, têm sido utilizados. Os genéricos relacionados à saúde são aplicáveis a quaisquer populações e condições clínicas, sendo conhecidos como perfis de saúde. Os específicos direcionam-se a um dado tipo de população, patologia ou função e são delineados com questões orientadas a sintomas e aspectos mais diretamente relacionados a situações clínicas (Garrat, et al., 2002). Em pacientes com DPOC, os instrumentos genéricos mais utilizados são o SF-36, o Sickness Impact Profile, o Nottingham Health Profile e o Quality of Well Being. Entre os específicos, encontram-se o Saint George Respiratory Questionnaire (SGRQ), o Seattle Obstructive Lung Disease Questionnaire (SOLDQ) e o Chronic Respiratory Questionnaire (CRQ), sendo que o primeiro destaca-se como o instrumento doença-específico de uso mais frequente (Mahler, 2000; Curtis, Patrick, 2003).

\subsection{QUALIDADE DE VIDA RELACIONADA À SAÚDE EM DPOC E FATORES ASSOCIADOS}

Nas últimas décadas, a avaliação da QVRS de pacientes com DPOC e dos fatores associados têm sido o foco de interesse em diversas publicações nacionais e internacionais.

Os dados da QVRS desses pacientes têm sido utilizados em estudos clínicos, como valores primários e como resultados pós intervenções (Jenkins, Rodriguez-Roisin, 2009). Um tratamento pode não impactar positivamente na mortalidade ou em indicadores de função pulmonar (por exemplo, o volume expiratório forçado no primeiro segundo - VEF1), mas pode trazer benefícios significantes na vitalidade do paciente e em outros aspectos de sua vida. Resultados como estes costumam ser mais valorizados pelos pacientes e familiares do que pelos clínicos. Contudo, a busca da melhor qualidade de vida 
possível, pelo alívio dos sintomas e pela melhoria do estado funcional, é um objetivo de grande importância também para os profissionais da saúde (Curtis, Patrick, 2003).

O estudo Inhaled Steroids in Obstructive Lung Disease in Europe, (ISOLDE), mostrou que a condição de saúde piora em uma velocidade mensurável, influenciada pela taxa e declínio da VEF1 e a frequência das exacerbações. O declínio pôde ser visto nos três domínios do SGRQ (sintomas, atividade e impacto), mostrando que todos os domínios sofrem piora progressiva e concomitante (Jones, Lareau, Mahler, 2005).

Com base nos instrumentos Short-Form 36 (SF-36) e Saint George Respiratory Questionnaire (SGRQ), Sant'Anna et al. (2003) avaliaram a QVRS de 36 pacientes com DPOC em oxigenoterapia de longa duração e 33 controles sem hipoxemia grave. $\mathrm{Na}$ comparação dos dois grupos, diferenças significativas foram encontradas nas dimensões Capacidade Funcional e Aspectos Sociais do SF-36. A oxigenoterapia prolongada não teve impacto em nenhuma das dimensões do SGRQ. Considerando o total de pacientes estudados (69), a dispneia foi o único fator que se correlacionou com todas as dimensões do SF-36 e do SGRQ, exceto para a dimensão Dor do SF-36.

Dourado et al.(2004) analisaram a influência de parâmetros clínicos: pressão inspiratória máxima (PImáx), teste de caminhada de seis minutos (TC6), Índice de Massa Corpórea (IMC), função pulmonar, gases sanguíneos, dinamometria de membros superiores e força muscular de quadríceps, na QVRS de 21 pacientes com DPOC. Tendo como variável dependente os escores do SGRQ, a regressão linear múltipla indicou como principais fatores independentes o IMC, com influência significativa nos domínios sintomas, impactos e no escore total, e o TC6, nos domínios atividades e impactos.

Como parte de um projeto multicêntrico (PLATINO), Camelier (2004) realizou um estudo de base populacional na região metropolitana de São Paulo, envolvendo 779 indivíduos com espirometria realizada no domicílio, dos quais 108 com diagnóstico de DPOC e 671 sem obstrução pulmonar (controles). Na avaliação da QVRS pelo SF-12, observou que os pacientes com DPOC apresentaram pontuações significativamente menores no componente físico, 
quando comparados aos controles, porém, o mesmo efeito não foi observado no componente mental. A dispneia, a bronquite crônica e a presença de crises de sibilos com dispneia foram fortes marcadores de diminuição do componente físico do SF-12, e, após o controle para obstrução, a limitação de fluxo pulmonar deixou de ser marcador isolado para diminuição da qualidade de vida.

O SF-36 e o SGRQ foram os instrumentos aplicados no estudo de Katsura, Yamada, Kida (2005), com 83 pacientes de DPOC. Baixos índices de massa corporal estiveram associados ao pior grau de dispneia e à pior QVRS, seja medida pelo instrumento genérico ou pelo doença-específico.

Garrido et al., (2006) conduziram o estudo EPIDEPOC na Espanha, com caráter multicêntrico, observacional e descritivo contando com 10.711 pacientes de atenção primária. Os autores utilizaram o instrumento SF-12 e obtiveram como fatores associados à qualidade de vida: sexo, VEF1, uso de oxigenoterapia, número admissões em pronto socorro e número de internações hospitalares.

Utilizando o Chronic Respiratory Questionnaire (CRQ) como instrumento de medida da QVRS, Berry, Adair, Rejeski (2006) pesquisaram a contribuição que a medida do Consumo Máximo de Oxigênio (VO2 máx) poderia trazer aos preditores. Após regressão hierárquica, encontraram que o $\mathrm{VO} 2$ máximo adiciona força às variáveis VEF1, TC6, tempo de subida de escala, função física, fadiga e ao domínio autocontrole. Já Cully et al. (2006) analisaram a influência da ansiedade e depressão na QVRS e constataram que o escore total de ansiedade foi a variável independente mais significativa em todos os modelos de regressão.

Torres et al. (2006) buscaram averiguar a influência do gênero nos determinantes de QVRS de 146 pacientes de uma clínica especializada em pneumologia. Utilizando o escore total do SGRQ como variável dependente, os autores observaram que, entre os homens, os fatores associados à QVRS foram: VEF1, VEF1/CVF (relação entre os valores do volume expiratório forçado no primeiro minuto e a capacidade vital forçada), $\mathrm{PaO} 2$ (pressão parcial de oxigênio), PaCO2 (pressão parcial de dióxido de carbono), exacerbações, índice de Charlson, TC6 (teste de caminhada de 6 minutos) e dispnéia, 
enquanto que para as mulheres, apenas VEF1, PaO2, exacerbações e dispnéia.

Cleland, Lee, Hall (2007) pesquisaram 110 pacientes em atendimento primário no Reino Unido, utilizando a escala HADS (Hospital Anxiety and Depression Scale) para mensurar os aspectos psicológicos, o EQ-5D (EuroQol 5 Dimensions) para a QVRS e o CCQ (Clinical COPD Questionnaire) para a sintomatologia. Os autores observaram que 1/5 desses pacientes apresentaram sintomas depressivos e quase 1/3, sintomas de ansiedade. Os que apresentavam maior escore para sintomatologia tendiam a ter maiores escores de ansiedade e depressão. Em relação à qualidade de vida, aqueles que apresentavam escores abaixo de 50 tinham 5 vezes mais chance de apresentarem depressão (em uma escala de 0 a 100, onde 0 é a pior condição e 100 a melhor).

Miravitlles et al. (2007) conduziram o estudo multicêntrico EVOCA (EVOlución de La CAlidad de vida en los pacientes com EPOC) durante dois anos, em uma amostra com 236 pacientes com DPOC estável em atendimento primário na Espanha. Os autores encontraram correlação fraca entre os escores do SGRQ com parâmetros clínicos e fisiológicos, sendo as variáveis: presença de tosse, grau de dispneia e tratamento com corticoides os melhores preditores de QVRS.

Ansari et al. (2007) analisaram a influência da frequência de exacerbações da DPOC, da força muscular, da idade e da dispneia sobre os escores do SGRQ, em uma amostra de 188 pacientes. Aqueles com maior número de exacerbações apresentaram pior QVRS do que os estáveis, porém, a idade e a força muscular foram as variáveis que permaneceram como preditoras significativas de QVRS.

Sanches et al. (2008) analisaram a relação entre gravidade da doença (VEF1) e QVRS, utilizando o Questionário de Vias Aéreas 20 (AQ20) e SGRQ e ajustando por outras variáveis (IMC, TC6, dispneia, saturação periférica de oxigênio ( $\mathrm{SpO} 2$ ), índice de comorbidade de Charlson e o índice BODE (Massa corpórea, obstrução das vias aéreas, dispneia e capacidade de exercício). $\mathrm{Na}$ análise bivariada, todas as variáveis, exceto o índice de Charlson, se correlacionaram com os escores do AQ20 e do SGRQ. Porém, na análise de 
regressão múltipla, apenas a dispneia permaneceu como variável preditora, explicando $38 \%$ e $36 \%$ da variância dos escores do AQ20 e do SGRQ, respectivamente.

Especial atenção às desordens psicológicas foi dada pelos autores Kühl, Schürmann, Rief (2008) em um estudo conduzido com 143 pacientes provenientes de uma clínica especializada em pneumologia na Alemanha. Os pacientes com diagnóstico de alguma afecção psicológica (ansiedade, depressão, somatização, pânico ou dependência química) apresentaram escores mais altos no domínio impactos e no total do SGRQ (onde quanto maior a pontuação, pior a QVRS). Foram selecionadas nove variáveis para o modelo de regressão múltipla, das quais seis permaneceram no modelo, em ordem de contribuição: somatização, depressão, TC6, gênero, VEF1 e presença de comorbidade cardíaca.

O impacto da dispneia na QVRS foi o objetivo do estudo de Francés et al. (2008), no qual foram estudados 101 pacientes com DPOC leve a grave. Os resultados indicaram que a dispneia basal esteve significativamente associada com variáveis de função pulmonar, estado emocional e broncoconstrição. Após análise multivariada, ansiedade, idade, TC6 e depressão foram os fatores associados à QVRS, medida pelo SGRQ. A ansiedade explicou sozinha $69 \%$ da variância. Os autores acreditam que um determinante importante da ansiedade nesses pacientes é a dispneia basal.

O ensaio clínico randomizado e multicêntrico NETT (The National Emphysema Treatment Trial), conduzido nos Estados Unidos com 1621 pacientes, investigou as relações da QVRS com a capacidade de exercício, função pulmonar e dispneia utilizando três instrumentos: SF-36, SGRQ e o Quality of Well Being (QWB) Scale. As variáveis dependentes foram os escores do SF36 e escore total do SGRQ. As correlações foram significativas com as variáveis VEF1, TC6 e dispneia nas análises univariadas, porém o efeito dessas variáveis era muito reduzido quando outras variáveis clínicas e psicológicas foram incluídas no modelo multivariado: capacidade de exercício, reabilitação pulmonar, uso suplementar de oxigênio, auto percepção, depressão, dispneia, uso de corticoide e sono. Os autores consideram que uma 
atenção maior deve ser dada às variáveis fisiopsicológicas e clínicas (Moy et al., 2009).

Os efeitos do grau de DPOC sobre a QVRS de 69 idosos foram avaliados no estudo de Oliveira et al. (2009). A classificação dos pacientes em graus moderado a grave foi baseada na espirometria (VEF1 e VEF1//CVF), conforme critério do Global Initiative for Obstructive and Lung Disease (GOLD) e a QVRS foi medida pelo SGRQ. Houve diferença significativa entre os grupos no escore total e nos domínios atividade e impacto, indicando que o nível de gravidade da doença influencia na QVRS de idosos com DPOC.

Ying-Xiang et al. (2009) pesquisaram a associação do índice BODE com a QVRS em 450 pacientes chineses com DPOC, por 12 meses. Foi verificado que o aumento gradativo do índice Bode (escala de 0 a 10, onde 10 é a pior condição) é acompanhado de aumento nos escores dos domínios e total do SGRQ. A análise de regressão múltipla com o método stepwise, incluindo as variáveis idade, sexo, fumo atual e o índice Bode, mostrou que o índice foi o fator mais fortemente associado à QVRS.

Em estudo transversal conduzido por Nunes et al., (2009) foi avaliado o impacto do sono na QVRS de pacientes com DPOC. Os autores comentam que as noites mal dormidas são um evento comum, sendo a terceira maior queixa em consultas com esses pacientes. Os resultados do estudo mostraram que a qualidade do sono foi responsável, isoladamente, por $37 \%$ da variância do escore total do SGRQ, o que confirma o poder preditivo do sono na QVRS desses pacientes.

Esteban et al. (2009) realizaram seguimento por cinco anos de 391 pacientes ambulatoriais para investigar o impacto das hospitalizações e das exacerbações na QVRS. Os autores dividiram os pacientes em três categorias classificadas segundo o número de internações: nenhuma, de uma a duas e de três ou mais. Apesar de a QVRS ter piorado nos três grupos ao longo dos 5 anos, aqueles que tiveram três ou mais internações, pontuaram significativamente mais em todos os domínios e no escore total do SGRQ. Após análise multivariada, o número de internações manteve-se como o principal fator associado à QVRS, seguido pela presença de comorbidades. 
O estudo de Mangueira et al. (2009) avaliou a correlação linear entre os escores do SGRQ e parâmetros clínicos (pressões expiratória e inspiratória máximas, VEF1, TC6 e IMC, idade, dispneia e fadiga) em 30 mulheres com DPOC. O IMC, a PEmáx (pressão expiratória máxima) e a VEF1 não apresentaram correlação com os escores do SGRQ, porém mantiveram correlação linear negativa com a idade e o TC6 e correlação positiva com a sensação de dispneia e fadiga, medida pela escala de Borg.

Dourado et al. (2009) analisaram os fatores associados à diferença clinicamente significativa da QVRS, após condicionamento físico em pacientes com DPOC. Trinta e cinco pacientes foram submetidos a 12 semanas de condicionamento físico e as variáveis analisadas foram: composição corporal, teste incremental e de endurance, TC6, força muscular periférica, PImáx (pressão inspiratória máxima), dispneia e o SGRQ. Após regressão logística, apenas a dispneia se manteve como fator associado.

Nos estudos que analisaram fatores associados à QVRS de pacientes com DPOC, observa-se grande heterogeneidade nas características e no tamanho das amostras, nos instrumentos utilizados e nas variáveis estudadas. Além disso, os resultados controversos em relação à influência das variáveis contribuem para a dificuldade em sumarizar os diversos fatores que afetam a QVRS dessa população.

No entanto, pode-se constatar a predominância de estudos avaliando a influência de sintomas, dados demográficos e relacionados à função pulmonar, sendo encontrados em menor frequência os que incluíram aspectos psicossociais e emocionais entre as variáveis analisadas (Kohler, Fish, Greene, 2002; Hu, Meek, 2005; Cully et al, 2006; Tze-Pin et al, 2007; Maurer et al, 2008), apesar da sua importância para a qualidade de vida dos pacientes.

Blinderman et al. (2009) consideram que a pesquisa sobre qualidade de vida de pacientes com DPOC não deve restringir-se ao estudo da relação com a sintomatologia, mas incluir uma gama maior de potenciais fatores socioeconômicos, psicológicos e, inclusive, de bem-estar espiritual. $\mathrm{Na}$ literatura internacional, o estudo destes autores é um dos únicos, em DPOC, que incluíram a espiritualidade entre as variáveis avaliadas. Ainda que o FACIT-Spirituality (Functional Assessment of Chronic Illness Therapy (FACIT) 
Spirituality Scale) não tenha se correlacionado significativamente com a qualidade de vida $(0.17 ; p=0.09)$, foi possível constatar que a fé, como fonte de conforto, estava relativamente preservada nos pacientes (escore médio de 2,5, em variação possível de 0 a 4).

No Brasil, Silva et al. (2009) analisaram as relações entre QVRS, avaliada pelo Seattle Obstructive Lung Disease Questionnaire (SOLDQ), e bem-estar existencial e religioso, pela Escala de Bem-Estar Espiritual (EBE). Os resultados mostraram uma correlação inversa e significativa entre a dimensão física do SOLDQ e o componente religioso da EBE, sugerindo que quanto maior o grau de incapacidade decorrente da doença, maior é o envolvimento com crenças e práticas religiosas.

Atualmente, há inúmeras indicações científicas de associação estatisticamente válida entre espiritualidade/religiosidade e saúde física e mental, sendo reconhecidas como importantes recursos de coping diante de eventos traumáticos e estressantes, como os que ocorrem no processo saúdedoença (Moreira-Almeida et al., 2006; Guimarães, Avezum, 2007 Panzini et al., 2007). Apesar disso, são escassos os estudos que abordam esse tema em doenças respiratórias crônicas, tanto em nível nacional como internacional.

Acredita-se que um maior conhecimento dos diversos fatores que influenciam, positiva ou negativamente, a qualidade de vida dos pacientes com DPOC, pode contribuir para o aprimoramento da prática clínica dos profissionais de saúde e, em última instância, melhorar a qualidade da assistência prestada a esses pacientes.

Este estudo tem o propósito de analisar as relações entre a QVRS de pacientes com DPOC e algumas características pessoais e clínicas, incluindo o bem-estar espiritual. 


\section{OBJETIVOS}

- Avaliar a qualidade de vida relacionada à saúde de pacientes com DPOC, considerando os sintomas da doença, as atividades físicas afetadas e os impactos psicossociais.

- Analisar a influência de fatores clínicos, sóciodemográficos e de bemestar espiritual, na qualidade de vida relacionada à saúde de pacientes com DPOC. 


\section{MÉTODO}

\subsection{TIPO DE ESTUDO}

Trata-se de um estudo descritivo e transversal, com abordagem quantitativa.

O estudo transversal tem como característica, a medição de todas as variáveis em uma única ocasião, permitindo analisar relações entre variáveis sem um período de acompanhamento posterior (Hulley et al., 2008).

\subsection{LOCAL DE ESTUDO}

O estudo foi realizado em um ambulatório de especialidades de pneumologia, que destina um dia de atendimento especial para pacientes com DPOC. O serviço integra o complexo ambulatorial do Hospital das Clínicas da Faculdade de Medicina da Universidade de São Paulo, um hospital público de grande porte, na cidade de São Paulo.

O ambulatório de pneumologia funciona desde 1996 e, em média, 30 pacientes com DPOC são atendidos semanalmente, às quintas feiras, no período das 8 às 12 horas.

À época da coleta de dados, a equipe do ambulatório era composta de dois técnicos de enfermagem, três médicos residentes em pneumologia, dois residentes em clínica médica, quatro médicos assistentes, dois fisioterapeutas e um farmacêutico.

Os pacientes são atendidos segundo horário de agendamento. Primeiramente, são colhidos dados como o peso, saturação de oxigênio e/ou espirometria pelos técnicos de enfermagem; em seguida, os pacientes são encaminhados para atendimento médico, em sala privativa. Ao término da 
consulta, os pacientes são agendados para retorno, que pode variar de uma semana a seis meses, dependendo das necessidades de seguimento clínico.

\subsection{AMOSTRA}

O estudo foi desenvolvido com amostra de conveniência composta de 70 pacientes atendidos no citado ambulatório de pneumologia, no período de novembro de 2007 a junho de 2008. Nesta época, estavam cadastrados no ambulatório, cerca de 1040 pacientes.

Os critérios de inclusão foram os seguintes:

- ter idade igual ou superior a 18 anos;

- ter sido diagnosticado com Doença Pulmonar Obstrutiva Crônica;

- estar em tratamento ambulatorial no local da coleta de dados há, pelo menos, seis meses (em função do tempo necessário para esclarecimento diagnóstico);

- concordar em participar do estudo, assinando o Termo de Consentimento Livre e Esclarecido ( Apêndice A).

\subsection{PROCEDIMENTOS PARA COLETA DOS DADOS}

O projeto obteve aprovação das Comissões de Ética em Pesquisa da instituição hospitalar (Protocolo 295/08) (Anexo 01) e da Escola de Enfermagem da USP (Processo 919/2008) (Anexo 02).

Os pacientes foram convidados a participar do estudo nos dias agendados para consulta e orientados sobre os seus objetivos, a garantia de sigilo e anonimato das informações fornecidas, o caráter voluntário da entrevista e a possibilidade de desistência a qualquer momento durante a pesquisa, sem prejuízo para o seu atendimento no serviço. 
Os dados foram coletados pela própria pesquisadora, por meio de entrevista, em local específico do ambulatório. O tempo total dispensado a cada paciente foi, em média, de uma hora e meia, sendo realizadas cerca de três entrevistas por dia de atendimento.

Todos os pacientes abordados concordaram em participar do estudo, assinando o Termo de Consentimento Livre e Esclarecido.

\subsection{INSTRUMENTOS DE COLETA DE DADOS}

Ficha de caracterização sóciodemográfica e clínica dos pacientes (Apêndice A) .

O instrumento de caracterização sóciodemográfica e clínica destinou-se à coleta dos seguintes dados: sexo, data de nascimento, peso, altura, trabalho atual, ocupação, renda familiar mensal, número de dependentes da renda, estado civil, escolaridade, religião, prática religiosa, tipo de prática religiosa, tempo de DPOC, presença de comorbidades, tipo de comorbidade, fumo atual, tempo de cessação de fumo, tempo de fumo, quantidade de maços/dia, grau de DPOC e relação VEF1/CVF.

A gravidade da DPOC foi classificada em quatro níveis, segundo os critérios da Iniciativa Global para a Doença Pulmonar Obstrutiva Crônica (GOLD, 2007):

\begin{tabular}{lll}
\hline Estádio I & Leve & VEF1/CVF $<0,7$ \\
& & VEF $1 \geq 80 \%$ do previsto \\
\hline Estádio II & Moderada & VEF1/CVF $<0,7$ \\
& & $50 \% \leq$ VEF $1 \leq 80 \%$ do previsto \\
\hline Estádio III & Grave & VEF1/CVF $<0,7$ \\
& & $30 \% \leq$ VEF $1 \leq 50 \%$ do previsto \\
\hline Estádio IV & Muito & VEF1/CVF $<0,7$ \\
& Grave & VEF $1<30 \%$ do previsto ou FEV1 $<50 \%$ do \\
& & previsto e insuficiência respiratória crônica
\end{tabular}

VEF1- Volume expiratório forçado no primeiro segundo; CVF - Capacidade vital forçada 
* Escala de Bem-Estar Espiritual (EBE), versão adaptada para o português por Volcan et al. (2003) (Anexo 03). Esta escala foi originalmente desenvolvida por Paloutzian e Ellison e tem sido considerada como referência para medida da espiritualidade (Marques, 2009). O instrumento é composto de 20 itens e mede o bem-estar espiritual em duas dimensões (ou sub -escalas): Bem-Estar Religioso (BER), avaliado pelos dez itens ímpares, e Bem-Estar Existencial (BEE), pelos dez itens pares. O BER refere-se a uma dimensão vertical de comunhão e relação pessoal com Deus ou com uma força superior e o BEE, a uma dimensão horizontal relacionada à satisfação e sentido de vida (Marques, 2009).

Os 20 itens da EBE são respondidos em uma escala de seis pontos, que varia de "concordo fortemente" a "discordo fortemente" (Anexo 04). Nove itens $(1,2,5,6,9,12,13,16$ e 18) têm conotação negativa e devem ser invertidos no cálculo dos escores. Os valores atribuídos aos itens de cada subescala são somados, obtendo-se escores que variam de 10 a 60 pontos. A soma dos escores de cada subescala resulta no escore total de Bem-Estar Espiritual (BEEt), que pode variar de 20 a 120 pontos. São sugeridos como pontos de corte, os intervalos de 20 a 40, 41 a 99 e 100 a 120, respectivamente para baixo, moderado e alto bem-estar espiritual. Para as duas subescalas, os intervalos são: de 10 a 20 (baixo), 21 a 49 (moderado) e 50 a 60 (alto) (Volcan et al., 2003; Gastaud et al., 2006; Marques, 2009), ou seja, quanto maior o escore, maior o bem-estar espiritual.

* Saint George Respiratory Questionnaire (SGRQ), versão adaptada para o português e validada por Sousa, Jardim, Jones (2000) (Anexo 05). O SGRQ foi originalmente desenvolvido por Jones et al. (1992) e é composto de duas partes e 50 itens, que abrangem três domínios: Sintomas (avalia o desconforto decorrente de sintomas respiratórios); Atividade (aborda situações e atividades físicas afetadas pela doença) e Impactos (aborda o impacto global na vida diária e no bem-estar).

A Parte 1 refere-se ao domínio Sintomas e avalia a frequência de tosse, produção de secreção, respiração ofegante e duração/frequência dos episódios 
de falta de ar, em relação ao período precedente de um ano. Esta parte é composta de oito questões, sendo sete do tipo Likert e uma "sim ou não".

A Parte 2 é composta por sete seções, com três questões do tipo Likert e as demais, do tipo "sim" ou "não". Refere-se aos domínios Atividade e Impactos. O domínio Atividade remete às atividades que podem causar falta de ar ou que são limitadas por ela e é composto de 16 itens; já o domínio Impactos, composto por 26 itens, cobre uma gama de fatores, incluindo a influência da doença no trabalho, sentimento de controle da doença, medo, estigmatização, necessidade da medicação, efeitos colaterais, expectativas de saúde e distúrbios da vida diária.

Todos os itens do instrumento recebem valores previamente definidos com base em ponderação empírica (Anexo 06), que devem ser somados em um total. Os itens com graduação nas respostas (questões do tipo Likert das duas partes) recebem a pontuação correspondente ao nível de resposta assinalado. Já os itens com respostas "sim" e "não" são pontuados somente para as respostas afirmativas.

Os escores dos domínios e do total dos itens têm uma pontuação máxima possível. Para se calcular os escores, somam-se os pontos de todas as respostas e a seguir, divide-se o resultado pelo valor máximo definido para cada domínio e para o total. Os escores são interpretados como uma percentagem dos valores máximos possíveis.

Cálculo dos escores:

- Sintomas: refere-se a todas as respostas assinaladas na Parte 1. Os pontos obtidos nas questões de 1 a 8 são somados. O valor máximo possível neste domínio é 662,5 .

- Atividade: refere-se à soma das respostas positivas da Seções 2 e 6 da Parte 2 do questionário. O valor máximo neste domínio é 1209,1.

- Impactos: refere-se à soma das respostas das Seções 1, 3, 4, 5, 7. O valor máximo é 2117,8 .

- Total: O escore total é calculado somando-se os pontos de todas as respostas do questionário. O valor máximo é 3989,4. 
Por fim, deve-se multiplicar a pontuação por 100; desta forma, o escore final resulta em escala de 0 a 100, ou seja, ele representa um percentual da pontuação máxima possível em cada domínio e no total. Pontuações mais altas indicam maior alteração na QVRS (Jones, 2008).

\subsection{DESCRIÇÃO DAS VARIÁVEIS DO ESTUDO}

Variáveis Dependentes:

- Escores do SGRQ (total e dos domínios Sintomas, Atividade e Impactos): variáveis quantitativas contínuas.

Variáveis Independentes:

- Idade: quantitativa discreta, representada pelo número de anos completos no momento da entrevista.

- Sexo: qualitativa dicotômica, representada pelas categorias masculino e feminino.

- Trabalho atual: qualitativa dicotômica, com respostas sim e não.

- Renda per capita: quantitativa contínua, obtida dividindo-se a renda familiar (em reais) pelo número de dependentes da renda.

- Situação conjugal: qualitativa dicotômica, representada pelas categorias: com companheiro e sem companheiro.

- Escolaridade: qualitativa nominal, classificada de forma dicotômica como alfabetizado e não alfabetizado.

- Religião: qualitativa nominal, classificada de forma dicotômica, como católica e não católica.

- Prática religiosa: qualitativa dicotômica, com respostas sim e não.

- Escores do domínio Bem-Estar Religioso (BER): quantitativa contínua.

- Escore do domínio Bem-Estar Existencial (BEE): quantitativa contínua.

- Índice de massa corporal (IMC): quantitativa contínua, calculada dividindo-se o peso (em quilos) pela altura ao quadrado (em metros). 
- Presença de comorbidades: qualitativa dicotômica, com respostas não e sim.

- Hábito de fumo: qualitativa nominal, classificada em nunca fumou, exfumante e fumante atual.

- Grau de DPOC: qualitativa ordinal, classificada em leve/moderado (estadios I, II) e grave/muito grave (estadios III ou IV).

- Tempo de DPOC: quantitativa discreta, representada pelo tempo (em anos) que a pessoa informa ter a doença.

- Anos-maço: quantitativa contínua, calculada pelo tempo de fumo (em anos) vezes o número de maços (por dia).

- VEF1: quantitativa contínua, representada pelo valor (em porcentagem) do volume expiratório forçado no primeiro segundo, durante o teste de espirometria.

\subsection{ANÁLISE DOS DADOS E TRATAMENTO ESTATÍSTICO}

Para a construção do banco de dados foi utilizado o Microsoft Excel e as análises estatísticas foram realizadas no software Statistical Package for the Social Sciences (SPSS) para Windows 16.0.

Estatística descritiva (frequência absoluta e percentual) foi utilizada para análise das variáveis qualitativas (sexo, trabalho atual, situação conjugal, escolaridade, religião, prática religiosa, tipo de prática religiosa, presença de comorbidades, tipo de comorbidade, hábito de fumo e grau de DPOC). Foram avaliadas a média, desvio-padrão, mediana, mínimo e máximo para as variáveis quantitativas (escores totais e dos domínios dos questionários SGRQ e EBE, idade, IMC, renda per capita, tempo de DPOC, anos-maço, tempo de fumo e VEF1).

A confiabilidade dos instrumentos SGRQ e EBE foi analisada pela consistência interna dos itens e domínios, utilizando-se o coeficiente Alfa de 
Cronbach. O valor de referência adotado como aceitável foi de Alfa $\geq 0,60$ (Hair et al., 2005).

Regressão linear múltipla foi a estratégia de análise adotada para identificar os preditores de QVRS entre as 17 variáveis independentes selecionadas. As variáveis qualitativas foram tratadas de forma dicotômica. $\mathrm{O}$ método utilizado foi o de busca sequencial backward. Todas as variáveis independentes são inicialmente analisadas em conjunto numa equação de regressão, sendo eliminadas aquelas que não contribuem significativamente. A seguir, as variáveis remanescentes são sucessivamente analisadas (Hair et al., 2005). Em cada modelo, foram eliminadas as variáveis com nível de significância $p \geq 0,10$, mantendo-se, portanto, aquelas com $p<0,10$ nos modelos preditivos finais. A colinearidade foi examinada por meio dos fatores de inflação da variância (VIF) para cada variável independente incluída nos modelos de regressão. Um valor de VIF>10 indica presença de colinearidade (Hair et al, 2005). A estatística de Durbin-Watson foi utilizada para verificar a presença de correlação serial nos resíduos $(1<x<3)$. 


\section{RESULTADOS}

\subsection{CARACTERIZAÇÃO SOCIODEMOGRÁFICA E CLÍNICA DOS PACIENTES}

A descrição das variáveis de caracterização sóciodemográfica e clínica está apresentada na Tabela 1, a seguir.

Tabela 1 - Caracterização sóciodemográfica e clínica dos pacientes com DPOC. São Paulo, 2008.

\begin{tabular}{|c|c|c|}
\hline Variáveis qualitativas & $\mathbf{n}$ & $\%$ \\
\hline $\begin{array}{l}\text { Sexo } \\
\text { masculino - feminino }\end{array}$ & $42-28$ & $60,0-40,0$ \\
\hline $\begin{array}{l}\text { Trabalho atual } \\
\text { sim - não }\end{array}$ & $9-61$ & $12,9-87,1$ \\
\hline $\begin{array}{l}\text { Situação conjugal } \\
\text { com companheiro } \\
\text { sem companheiro }\end{array}$ & $\begin{array}{l}50 \\
20\end{array}$ & $\begin{array}{l}71,4 \\
28,6\end{array}$ \\
\hline $\begin{array}{l}\text { Escolaridade } \\
\text { analfabeto } \\
\text { nível fundamental } \\
\text { nível médio e superior }\end{array}$ & $\begin{array}{l}11 \\
46 \\
13\end{array}$ & $\begin{array}{l}15,7 \\
65,7 \\
18,6\end{array}$ \\
\hline $\begin{array}{l}\text { Religião } \\
\text { católica } \\
\text { evangélica } \\
\text { espírita/candomblé }\end{array}$ & $\begin{array}{c}47 \\
15 \\
8\end{array}$ & $\begin{array}{l}67,1 \\
21,4 \\
10,4\end{array}$ \\
\hline $\begin{array}{l}\text { Prática religiosa } \\
\text { sim* - não }^{*}\end{array}$ & $61-9$ & $87,1-12,9$ \\
\hline $\begin{array}{l}\text { Doenças associadas } \\
\text { sim - não }\end{array}$ & $38-32$ & $54,3-45,7$ \\
\hline $\begin{array}{l}\text { Tipo de doença associada }(\mathbf{n}=\mathbf{4 3}) \\
\text { hipertensão arterial } \\
\text { diabetes, cardiopatias e doenças } \\
\text { osteomusculares }\end{array}$ & $\begin{array}{l}29 \\
14\end{array}$ & $\begin{array}{l}67,4 \\
32,6\end{array}$ \\
\hline $\begin{array}{l}\text { Ex-fumantes } \\
\text { sim - não }\end{array}$ & $57-13$ & $81,4-18,6$ \\
\hline $\begin{array}{l}\text { Grau de DPOC } \\
\text { leve } \\
\text { moderado } \\
\text { grave } \\
\text { muito grave }\end{array}$ & $\begin{array}{c}1 \\
22 \\
35 \\
12\end{array}$ & $\begin{array}{c}1,4 \\
31,5 \\
50,0 \\
17,1\end{array}$ \\
\hline
\end{tabular}


Continuação

\begin{tabular}{lcccc}
\hline Variáveis quantitativas & média (dp) & mediana & min. & máx. \\
\hline Idade & $64,24(10,22)$ & 65 & 43 & 81 \\
Índice de Massa Corporal & $25,04(5,05)$ & 25,15 & 14,87 & 36,63 \\
Renda mensal familiar (R\$) & $1129,10(891,79)$ & 900,00 & 280,00 & 5000,00 \\
Renda mensal per capita (R\$) & $486,09(424,53)$ & 375,00 & 75,00 & 2500,00 \\
No de dependentes da renda & $2,71(1,44)$ & 2 & 1 & 8 \\
Tempo de DPOC (anos) & $9,17(5,89)$ & 7,50 & 1 & 20 \\
Anos/maço & $55,08(35,67)$ & 45 & 9 & 150 \\
VEF1 (\% pred.) & $44,81(14,33)$ & 42,00 & 19,00 & 80,00 \\
\hline
\end{tabular}

${ }^{*}$ As práticas religiosas mais freqüentemente relatadas foram a oração $(n=45-63,4 \%)$ e a frequência à missa $(n=39-55,7 \%)$.

Constata-se na Tabela 1, o predomínio de pacientes do sexo masculino (42-60\%), sem vínculo empregatício (61-87,1\%), que viviam com companheiro (50-71,4\%), de baixa escolaridade (46-65,7\% com nível fundamental e 11$15,7 \%$ analfabetos) e baixa renda ( $R \$ 1129,10 ; d p=891,79)$. Os pacientes tinham, em média, 64,24 anos ( $d p=10,22)$. A maioria era da religião católica $(47-67,1 \%)$ e $61(87,1 \%)$ informaram ter algum tipo de prática religiosa. Entre elas, as mais freqüentes foram a oração, citada 45 vezes $(63,4 \%)$ e a frequência à missa, com 39 citações $(55,7 \%)$.

Quanto aos dados clínicos, 38 pacientes relataram ter doenças associadas (54,3\%), sendo a hipertensão arterial a mais frequente (29-76,3\%). Declararam-se ex-fumantes 57 pacientes $(81,4 \%)$ e na classificação GOLD do grau de DPOC, $47(67,1 \%)$ encontravam-se nos níveis grave e muito grave. $O$ tempo médio de DPOC foi de 9,17 anos $(d p=5,89)$ e o consumo de cigarros, medido em anos/maço, foi de 55,08 ( $d p=35,67)$, variando de 9 a 150. Como medida de função pulmonar, o valor médio do VEF1 foi de $44,81 \%$ do predito $(d p=14,33)$. O IMC apresentou média de 25,04 ( $d p=5,05)$, no limite de normalidade. 


\subsection{ANÁLISE DA CONSISTÊNCIA INTERNA DO SAINT GEORGE RESPIRATORY QUESTIONNAIRE E DA ESCALA DE BEM-ESTAR ESPIRITUAL}

Os instrumentos padronizados utilizados neste estudo foram previamente testados quanto à sua confiabilidade. Os resultados estão apresentados na Tabela 2.

Tabela 2 - Coeficiente a de Cronbach dos itens e domínios do Saint George Respiratory Questionnaire e da Escala de Bem Estar Espiritual. São Paulo, 2008.

\begin{tabular}{lcc}
\hline $\begin{array}{c}\text { Instrumentos e } \\
\text { Domínios }\end{array}$ & a de Cronbach & Total de itens \\
\hline SGRQ & & \\
Sintomas & 0,69 & 8 \\
Atividade & 0,71 & 16 \\
Impacto & 0,83 & 26 \\
Total & 0,88 & 50 \\
\hline EBE & & \\
Religioso & 0,86 & 10 \\
Existencial & 0,59 & 10 \\
$\quad$ Total & 0,83 & 20 \\
\hline SRQ=Saint George Respiratory Questionnaire; EBE=Escala de Bem Estar \\
Espiritual,
\end{tabular}

Os dados da Tabela 3 mostram que ambos os instrumentos apresentaram valores satisfatórios de consistência interna ( $\alpha$ de Cronbach > 0,60 ), exceto o valor limítrofe de 0,59 obtido na dimensão Existencial da EBE.

\subsection{AVALIAÇÃO DA QUALIDADE DE VIDA RELACIONADA À SAÚDE}

\subsubsection{Estatística descritiva do SGRQ e da EBE}

Cabe lembrar que os escores do SGRQ representam uma porcentagem da pontuação máxima possível (no total e nos domínios), podendo, portanto, variar de 0 a 100. Maiores pontuações indicam pior condição. Na EBE, o escore 
total varia de 20 a 120 e, em cada domínio, a variação possível é de 10 a 60 . Valores mais altos correspondem a maior bem-estar espiritual, religioso e existencial.

A Tabela 3 apresenta as análises descritivas do SGRQ e da EBE.

Tabela 3 - Estatística descritiva dos escores do Saint George Respiratory Questionnaire e da Escala de Bem Estar Espiritual. São Paulo, 2008.

\begin{tabular}{lcccc}
\hline Instrumento & Média (dp) & Mediana & Mínimo & Máximo \\
\hline SGRQ escore total (\%) & $63(15)$ & 64 & 19 & 93 \\
Domínio Sintomas (\%) & $65(18)$ & 67 & 27 & 95 \\
Domínio Atividade (\%) & $72(15)$ & 73 & 30 & 100 \\
Domínio Impactos (\%) & $57(19)$ & 57 & 04 & 94 \\
EBE total & $94,87(13,56)$ & 96 & 64 & 119 \\
Bem estar religioso & $51,50(8,68)$ & 54 & 24 & 60 \\
Bem estar existencial & $43,37(6,76)$ & 42,50 & 27 & 59 \\
\hline
\end{tabular}

SGRQ = Saint George Respiratory Questionnaire, EBE = Escala de Bem Estar Espiritual

Em relação ao $S G R Q$, o domínio Atividade obteve a maior pontuação (72, $d p=15)$, seguido do domínio Sintomas $(65, d p=15)$. O domínio Impactos foi o menos afetado $(57, d p=19)$, porém com a mais ampla variação nos escores (de 4 a 94).

Para a Escala de Bem Estar Espiritual, o escore total foi de 94,87 $(d p=13,56)$, tendo maior contribuição do domínio Religioso $(51,50 ; d p=8,68)$ do que do Existencial $(43,37, d p=6,76)$.

6.3.2 Frequência de respostas aos itens dos domínios do SGRQ

As Tabelas 4, 5 e 6 apresentam a freqüência de respostas aos itens dos domínios Sintomas, Atividades e Impactos do SGRQ, respectivamente. 
Tabela 4 - Frequência de pacientes nas categorias de resposta dos itens do domínio Sintomas do Saint George Respiratory Questionnaire. São Paulo 2008.

\begin{tabular}{|c|c|c|c|c|c|}
\hline \multirow[b]{2}{*}{ Domínio Sintomas } & \multicolumn{5}{|c|}{ Categorias de resposta } \\
\hline & $\begin{array}{c}\text { maioria } \\
\text { dos dias } \\
\text { da semana } \\
\mathrm{n}(\%) \\
\end{array}$ & $\begin{array}{c}\text { vários } \\
\text { dias na } \\
\text { semana } \\
\text { n (\%) }\end{array}$ & $\begin{array}{c}\text { alguns } \\
\text { dias no } \\
\text { mês } \\
n(\%)\end{array}$ & $\begin{array}{c}\text { só com } \\
\text { infecções } \\
\text { respiratórias } \\
n(\%) \\
\end{array}$ & $\begin{array}{l}\text { nunca } \\
n(\%)\end{array}$ \\
\hline Durante o último ano tossi & $27(38,6)$ & $11(15,7)$ & $9(12,9)$ & $19(27,1)$ & $4(5,7)$ \\
\hline $\begin{array}{l}\text { Durante o último ano tive } \\
\text { catarro }\end{array}$ & $22(31,4)$ & $12(17,1)$ & $10(14,3)$ & $17(24,3)$ & $9(12,9)$ \\
\hline $\begin{array}{l}\text { Durante o último ano tive } \\
\text { falta de ar }\end{array}$ & $52(74,3)$ & $9(12,9)$ & $6(8,6)$ & $2(2,9)$ & $1(1,4)$ \\
\hline $\begin{array}{l}\text { Durante o último ano tive } \\
\text { "chiado no peito" }\end{array}$ & $28(40,0)$ & $8(11,4)$ & $8(11,4)$ & $10(14,3)$ & $16(22,9)$ \\
\hline \multirow[b]{2}{*}{ Quantas crises graves } & $\begin{array}{c}\text { mais de } 3 \\
\mathrm{n}(\%)\end{array}$ & $\begin{array}{c}3 \\
n(\%)\end{array}$ & $\begin{array}{c}2 \\
n(\%)\end{array}$ & $\begin{array}{c}1 \\
n(\%)\end{array}$ & $\begin{array}{c}0 \\
n(\%)\end{array}$ \\
\hline & $18(25,7)$ & $8(11,4)$ & $7(10,0)$ & $14(20,0)$ & $23(32,9)$ \\
\hline \multirow{2}{*}{ Quanto tempo durou $(n=47)$} & $\begin{array}{c}\text { 1sem. ou + } \\
\text { n (\%) }\end{array}$ & $\begin{array}{c}3 \mathrm{~d} \text { ou }+ \\
\mathrm{n}(\%)\end{array}$ & $\begin{array}{c}\text { 1ou 2d } \\
\text { n (\%) }\end{array}$ & $\begin{array}{c}\text { menos de1 dia } \\
\mathrm{n}(\%)\end{array}$ & \\
\hline & $23(48,9)$ & $6(12,8)$ & $7(14,9)$ & $1(23,4)$ & \\
\hline \multirow[b]{2}{*}{$\begin{array}{l}\text { Quantos dias bons você teve } \\
\text { em uma semana habitual }\end{array}$} & $\begin{array}{c}0 \\
n(\%)\end{array}$ & $\begin{array}{l}1 \text { ou } 2 \\
\mathrm{n}(\%)\end{array}$ & $\begin{array}{l}3 \text { ou } 4 \\
\mathrm{n}(\%)\end{array}$ & $\begin{array}{c}\text { quase todos } \\
\mathrm{n}(\%)\end{array}$ & $\begin{array}{l}\text { todos } \\
\mathrm{n}(\%)\end{array}$ \\
\hline & $20(28,6)$ & $19(27,1)$ & $15(21,4)$ & $12(17,1)$ & $4(5,7)$ \\
\hline \multirow[b]{2}{*}{$\begin{array}{l}\text { Se teve chiado no peito, ele } \\
\text { é pior de manhã? }(n=54)\end{array}$} & $\operatorname{sim}_{\mathrm{n}(\%)}$ & $\begin{array}{c}\text { não } \\
\text { n (\%) }\end{array}$ & & & \\
\hline & $17(31,5)$ & $37(68,5)$ & & & \\
\hline
\end{tabular}

O principal sintoma relatado foi a falta de ar, presente em $52(74,3 \%)$ dos pacientes na maioria dos dias da semana. A tosse e o chiado no peito também foram bastante frequentes, porém $16(22,9 \%)$ pacientes nunca tiveram chiado. Uma grande parte $(47-67,1 \%)$ teve pelo menos uma crise grave, com duração de uma semana ou mais (23-48,9\%). Vinte pacientes $(28,6 \%)$ consideraram que, numa semana habitual, nenhum dia foi bom e outros $19(27,1 \%)$, que apenas um ou dois foram bons. 
Tabela 5 - Frequência de pacientes nas categorias de resposta dos itens do domínio Atividade do Saint George Respiratory Questionnaire. São Paulo 2008.

\begin{tabular}{|c|c|c|}
\hline \multirow{2}{*}{$\begin{array}{l}\text { Domínio Atividade } \\
\text { Falta de ar: }\end{array}$} & \multicolumn{2}{|c|}{ Categorias de resposta } \\
\hline & $\underset{n}{\operatorname{Sim}(\%)}$ & $\begin{array}{l}\text { Não } \\
\text { n (\%) }\end{array}$ \\
\hline Sentado ou deitado & $24(34,3)$ & $46(65,7)$ \\
\hline Tomando banho ou vestindo & $55(78,6)$ & $15(21,4)$ \\
\hline Caminhando dentro de casa & $23(32,9)$ & $47(67,1)$ \\
\hline Caminhando em terreno plano & $29(41,4)$ & $41(58,6)$ \\
\hline Subindo um lance de escada & $65(92,9)$ & $5(7,1)$ \\
\hline Subindo ladeiras & $67(95,7)$ & $3(4,3)$ \\
\hline Praticando esportes ou jogos & $70(100)$ & - \\
\hline Atividades afetadas pela respiração: & $\operatorname{Sim}_{n(\%)}$ & $\begin{array}{l}\text { Não } \\
\text { n (\%) }\end{array}$ \\
\hline -Leva muito tempo para lavar-me ou vestir-me & $24(34,3)$ & $46(65,7)$ \\
\hline $\begin{array}{l}\text {-Demoro muito tempo ou não consigo tomar banho de } \\
\text { chuveiro ou na banheira }\end{array}$ & $23(32,9)$ & $47(67,1)$ \\
\hline $\begin{array}{l}\text {-Ando mais devagar que as outras pessoas, ou tenho que } \\
\text { parar para descansar }\end{array}$ & $61(87,1)$ & $9(12,9)$ \\
\hline $\begin{array}{l}\text {-Demoro muito tempo para realizar tarefas como o trabalho } \\
\text { de casa, ou tenho que parar para descansar }\end{array}$ & $58(82,9)$ & $12(17,1)$ \\
\hline $\begin{array}{l}\text {-Quando subo um lance de escada, vou muito devagar, ou } \\
\text { tenho que parar para descansar }\end{array}$ & $60(85,7)$ & $10(14,3)$ \\
\hline $\begin{array}{l}\text {-Se caminho mais depressa, tenho que parar para } \\
\text { descansar ou ir mais devagar }\end{array}$ & $66(94,3)$ & $4(5,7)$ \\
\hline $\begin{array}{l}\text { - Tenho dificuldade para desenvolver atividades como: subir } \\
\text { ladeiras, carregar objetos subindo escadas, dançar, praticar } \\
\text { esporte leve }\end{array}$ & $69(98,6)$ & $1(1,4)$ \\
\hline $\begin{array}{l}\text {-Tenho dificuldades para desenvolver atividades como: } \\
\text { carregar grandes pesos, fazer "cooper" ou nadar }\end{array}$ & $70(100)$ & - \\
\hline $\begin{array}{l}\text { - Tenho dificuldade para desenvolver atividades como: } \\
\text { trabalho manual pesado, correr, andar de bicicleta, nadar } \\
\text { rápido, ou praticar esportes de competição. }\end{array}$ & $70(100)$ & - \\
\hline
\end{tabular}

No domínio Atividade, verifica-se que a maioria dos pacientes afirmou sentir falta de ar tomando banho ou se vestindo (55-78,6\%), subindo um lance de escada $(65-92,9 \%)$ ou ladeiras $(67-95,7 \%)$ e todos eles $(100 \%)$, quando praticavam esportes ou jogos. Nota-se que cerca de um terço dos pacientes sentia falta de ar mesmo quando sentados ou deitados (24-34,3\%), caminhando dentro de casa (23-32,9\%) ou em terreno plano (29-41,4\%).

A falta de ar não afetou o tempo para tomar banho ou para se vestir (46$65,7 \%)$ e tampouco a sua capacidade de cuidar da higiene pessoal (47-67,1\%). Ainda assim, a falta de ar trouxe prejuízo nesses aspectos para mais de $30 \%$ 
dos pacientes. De modo geral, os pacientes percebiam-se como mais lentos do que outras pessoas, tendo que parar para descansar quando estavam andando (61-87,1\%), executando trabalhos domésticos (58-82,9\%), subindo um lance de escada $(60-85,7 \%)$ ou caminhando mais depressa (66-94,3\%). Atividades físicas de moderada intensidade eram realizadas com dificuldade $(98,6 \%)$ e nenhum paciente se sentia capaz de realizar atividades vigorosas. 
Tabela 6 - Frequência de pacientes nas categorias de resposta dos itens do domínio Impactos do Saint George Respiratory Questionnaire. São Paulo 2008.

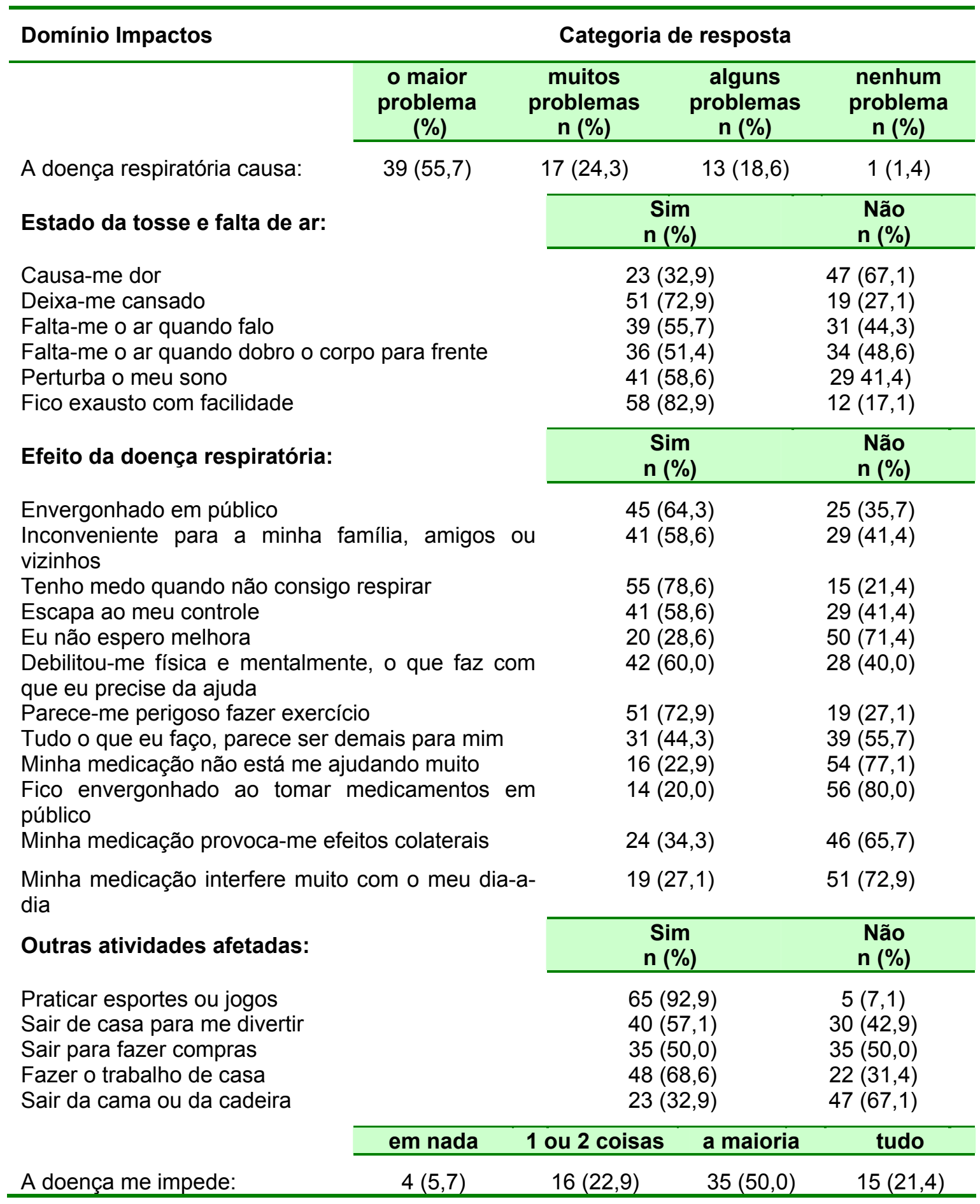

Apenas um paciente respondeu que a doença respiratória não lhe causa nenhum problema. Para a maioria (39-55,7\%), ela é o seu maior problema e outros $(17-24,3 \%)$ consideram que ela causa muitos problemas. A tosse e a 
falta de ar fazem com que se sintam exaustos com facilidade $(58-82,9 \%)$, cansados (51-72,9\%), além de prejudicar o sono (41-58,6\%) e a fala (39$55,7 \%$ ). A doença provoca nos pacientes sensação de medo (55-78,6\%), perigo (51-72,9\%), vergonha (45-64,3\%), debilidade física e mental (42-60,0\%), de ser inconveniente para os outros $(41-58,6 \%)$ e de falta de controle sobre ela (41$58,6 \%)$. Além disso, afeta a prática de esportes (65-98,9\%), o trabalho de casa (48-68,6\%) e saídas para diversão (40-57,1\%) ou compras (35-50,0\%). 


\subsection{ANÁLISE DE REGRESSÃO LINEAR MÚLTIPLA}

Nas Tabelas 7, 8, e 9, a seguir, estão apresentados os resultados da análises de regressão linear múltipla para os domínios e escore total do SGRQ.

Tabela 7 - Regressão linear múltipla para o domínio Sintomas do Saint George Respiratory Questionnaire. São Paulo, 2008.

\begin{tabular}{|c|c|c|c|c|c|c|c|}
\hline Modelo & $\begin{array}{l}\text { Variáveis que } \\
\text { permaneceram }\end{array}$ & $\begin{array}{c}\text { Coeficiente } \\
\beta\end{array}$ & P-valor & VIF & & & \\
\hline \multirow[t]{19}{*}{1} & Constante & 160,268 & 0,00 & & & & \\
\hline & Sexo & $-9,046$ & 0,11 & 1,766 & & & \\
\hline & Trabalho atual & $-13,446$ & 0,12 & 1,929 & & & \\
\hline & Sit. conjugal & 3,773 & 0,53 & 1,703 & & & \\
\hline & Escolaridade & $-17,226$ & 0,02 & 1,472 & & & \\
\hline & Religião & $-5,491$ & 0,28 & 1,293 & & & \\
\hline & Prática & 7,502 & 0,31 & 1,390 & & & \\
\hline & religiosa & & & & & & \\
\hline & Comorbidade & $-3,117$ & 0,57 & 1,748 & & & \\
\hline & Hábito de fumo & $-12,062$ & 0,09 & 1,634 & & & \\
\hline & Grau de DPOC & 8,849 & 0,38 & 5,083 & & & \\
\hline & Idade & $-0,212$ & 0,47 & 2,004 & & & \\
\hline & IMC & $-0,964$ & 0,09 & 1,867 & & & \\
\hline & Renda per capita & $-0,002$ & 0,72 & 1,581 & & & \\
\hline & Tempo de DPOC & 1,229 & 0,01 & 1,531 & & & \\
\hline & Anos /maço & ,095 & 0,21 & 1,778 & & & \\
\hline & VEF $1(\%)$ & $-0,214$ & 0,50 & 4,648 & & & \\
\hline & Escore de BER & 0,095 & 0,80 & 2,489 & & & \\
\hline & Escore de BEE & $-0,808$ & 0,08 & 2,147 & & & \\
\hline \multirow[t]{5}{*}{16} & & & & & $\mathbf{R}^{2}$ & $\mathbf{R}^{2} \mathbf{a j}$ & DW \\
\hline & & & & & 0,129 & 0,103 & 2,071 \\
\hline & Constante & 72,819 & 0,00 & & & & \\
\hline & Escolaridade & $-15,152$ & 0,01 & 1,000 & & & \\
\hline & Tempo de DPOC & 0,612 & 0,09 & 1,000 & & & \\
\hline
\end{tabular}

Sit. conjugal = situação conjugal; DPOC = Doença Pulmonar Obstrutiva Crônica; IMC = Índice de Massa Corporal; VEF 1 = Volume Expiratório Forçado no primeiro segundo; BER $=$ Bem Estar religioso; $\mathrm{BEE}=$ Bem Estar Existencial.

$\mathrm{R}^{2}=$ coeficiente de correlação múltipla; $\mathrm{R}^{2}$ aj coeficiente de correlação múltipla ajustado, DW = Estatística de Durbin- Watson. 
A Tabela 7 mostra que, para o domínio Sintomas, a regressão estabilizou no $16^{\circ}$ modelo, permanecendo como variáveis preditoras a escolaridade e o tempo de DPOC. Observa-se que a escolaridade teve um coeficiente $\beta$ negativo de 15,15 e um nível de significância de $p=0,01$, o que significa que ser alfabetizado diminui em cerca de 15 pontos o escore do domínio Sintomas. O VIF de 1,0 mostra que as variáveis não são colineares. O $\mathrm{R}^{2}$ ajustado indica que as duas variáveis explicam $10,3 \%$ da variabilidade do escore de Sintomas e a estatística de Durbin-Watson não revelou correlação serial. 
Tabela 8 - Regressão linear múltipla para o domínio Atividade do Saint George Respiratory Questionnaire. São Paulo, 2008.

\begin{tabular}{|c|c|c|c|c|c|c|c|}
\hline Modelo & $\begin{array}{l}\text { Variáveis que } \\
\text { permaneceram }\end{array}$ & $\begin{array}{c}\text { Coeficiente } \\
\beta\end{array}$ & P-valor & VIF & & & \\
\hline \multirow[t]{19}{*}{1} & Constante & 94,340 & 0,00 & & & & \\
\hline & Sexo & 2,832 & 0,53 & 1,766 & & & \\
\hline & Trabalho atual & $-15,265$ & 0,03 & 1,929 & & & \\
\hline & Sit. conjugal & 1,040 & 0,83 & 1,703 & & & \\
\hline & Escolaridade & $-11,729$ & 0,03 & 1,472 & & & \\
\hline & Religião & $-3,044$ & 0,45 & 1,293 & & & \\
\hline & Prática & 5,112 & 0,38 & 1,390 & & & \\
\hline & religiosa & & & & & & \\
\hline & Comorbidade & $-8,436$ & 0,06 & 1,748 & & & \\
\hline & Hábito de fumo & $-5,758$ & 0,31 & 1,634 & & & \\
\hline & Grau de DPOC & $-3,645$ & 0,65 & 5,083 & & & \\
\hline & Idade & $-0,003$ & 0,99 & 2,004 & & & \\
\hline & IMC & 0,038 & 0,93 & 1,867 & & & \\
\hline & Renda per capita & 0,006 & 0,20 & 1,581 & & & \\
\hline & Tempo de DPOC & 0,011 & 0,97 & 1,531 & & & \\
\hline & Anos /maço & 0,048 & 0,42 & 1,778 & & & \\
\hline & VEF $1(\%)$ & $-0,038$ & 0,88 & 4,648 & & & \\
\hline & Escore de BER & 0,523 & 0,09 & 2,489 & & & \\
\hline & Escore de BEE & $-0,872$ & 0,02 & 2,147 & & & \\
\hline \multirow[t]{8}{*}{13} & & & & & $\mathbf{R}^{2}$ & $R^{2}$ aj & DW \\
\hline & & & & & 0,300 & 0,245 & 2,350 \\
\hline & Constante & 105,053 & 0,00 & & & & \\
\hline & Trabalho atual & $-12,215$ & 0,02 & 1,130 & & & \\
\hline & Escolaridade & $-10,753$ & 0,02 & 1,095 & & & \\
\hline & Comorbidade & $-8,996$ & 0,01 & 1,177 & & & \\
\hline & Escore de BER & 0,416 & 0,07 & 1,508 & & & \\
\hline & Escore de BEE & $-0,878$ & 0,00 & 1,481 & & & \\
\hline
\end{tabular}

Sit. conjugal = situação conjugal; DPOC = Doença Pulmonar Obstrutiva Crônica; IMC = Índice de Massa Corporal; VEF 1 = Volume Expiratório Forçado no primeiro segundo; BER $=$ Bem Estar religioso; $\mathrm{BEE}=$ Bem Estar Existencial.

$\mathrm{R}^{2}=$ coeficiente de correlação múltipla, $\mathrm{R}^{2}$ aj coeficiente de correlação múltipla ajustado, DW = Estatística de Durbin- Watson.

A Tabela 8 mostra que o modelo de regressão estabilizou com cinco variáveis independentemente associadas ao domínio Atividade: trabalho atual, escolaridade, presença de comorbidades, escore de BER e escore de BEE. Os valores do VIF (menores que 1,5) denotam ausência de colinearidade entre as 
variáveis. Os fatores que mais contribuíram para a variação no escore total de Atividade foram: ter um trabalho atual $(\beta=-12,215)$, ser alfabetizado ( $\beta=-$ $10,753)$, presença de comorbidade $(\beta=-8,996)$ e BEE $(\beta=-0,878)$, com menor contribuição do $\operatorname{BER}(-\beta=0,416)$. $O$ coeficiente $R^{2}$ ajustado indica que $24,5 \%$ da variabilidade é explicada por essas variáveis. 
Tabela 9 - Regressão linear múltipla para o domínio Impactos do Saint George Respiratory Questionnaire. São Paulo, 2008.

\begin{tabular}{|c|c|c|c|c|c|c|c|}
\hline Modelo & $\begin{array}{l}\text { Variáveis que } \\
\text { permaneceram }\end{array}$ & $\begin{array}{c}\text { Coeficiente } \\
\beta\end{array}$ & P-valor & VIF & & & \\
\hline \multirow[t]{18}{*}{1} & Constante & 102,522 & 0,00 & & & & \\
\hline & Sexo & 9,215 & 0,11 & 1,766 & & & \\
\hline & Trabalho atual & $-9,208$ & 0,29 & 1,929 & & & \\
\hline & Sit. conjugal & 9,858 & 0,11 & 1,703 & & & \\
\hline & Escolaridade & $-19,286$ & 0,01 & 1,472 & & & \\
\hline & Religião & $-5,363$ & 0,29 & 1,293 & & & \\
\hline & $\begin{array}{l}\text { Prática } \\
\text { religiosa }\end{array}$ & $-3,392$ & 0,64 & 1,390 & & & \\
\hline & Comorbidade & $-0,401$ & 0,94 & 1,748 & & & \\
\hline & Hábito de fumo & 9,259 & 0,19 & 1,634 & & & \\
\hline & Grau de DPOC & $-6,001$ & 0,55 & 5,083 & & & \\
\hline & Idade & $-0,071$ & 0,81 & 2,004 & & & \\
\hline & IMC & $-0,843$ & 0,14 & 1,867 & & & \\
\hline & Renda per capita & 0,000 & 0,96 & 1,581 & & & \\
\hline & Tempo de DPOC & 0,493 & 0,27 & 1,531 & & & \\
\hline & Anos /maço & $-0,130$ & 0,09 & 1,778 & & & \\
\hline & VEF $1(\%)$ & 0,102 & 0,75 & 4,648 & & & \\
\hline & Escore de BER & 0,413 & 0,28 & 2,489 & & & \\
\hline & Escore de BEE & $-1,038$ & 0,03 & 2,147 & & & \\
\hline \multirow[t]{4}{*}{16} & & & & & $\mathbf{R}^{2}$ & $R^{2} a j$ & DW \\
\hline & Constante & 80,087 & 0,00 & & 0,227 & 0,204 & 2,104 \\
\hline & Escolaridade & $-19,326$ & 0,00 & 1,035 & & & \\
\hline & Anos /Maço & $-0,131$ & 0,03 & 1,035 & & & \\
\hline
\end{tabular}

Sit. conjugal = situação conjugal; DPOC = Doença Pulmonar Obstrutiva Crônica; IMC = Índice de Massa Corporal; VEF $1=$ Volume Expiratório Forçado no primeiro segundo; $B E R=$ Bem Estar religioso; $\mathrm{BEE}=\mathrm{Bem}$ Estar Existencial.

$\mathrm{R}^{2}$ = coeficiente de correlação múltipla, $\mathrm{R}^{2} a j=$ coeficiente de correlação múltipla ajustado, DW = Estatística de Durbin- Watson.

A regressão para o domínio Impactos estabilizou no $16^{\circ}$ modelo, mantendo-se como variáveis preditoras a escolaridade e a carga tabágica (anos/maço). A maior contribuição foi da variável escolaridade que teve um coeficiente $\beta$ negativo de 19,33 e um nível de significância de $p=0,002$. Os valores de VIF indicam que não houve colinearidade e o valor de $\mathrm{R}^{2}$ indica cerca de $20,4 \%$ da variabilidade é explicada por essas variáveis e o Durbin Watson não revelou correlação serial. 
Tabela 10 - Regressão linear múltipla para o escore total do Saint George Respiratory Questionnaire. São Paulo, 2008.

\begin{tabular}{|c|c|c|c|c|c|c|c|}
\hline Modelo & $\begin{array}{l}\text { Variáveis que } \\
\text { permaneceram }\end{array}$ & $\begin{array}{c}\text { Coeficiente } \\
\beta\end{array}$ & P-valor & VIF & & & \\
\hline \multirow[t]{18}{*}{1} & Constante & 357,130 & 0,00 & & & & \\
\hline & Sexo & 3,002 & 0,81 & 1,766 & & & \\
\hline & Trabalho atual & $-37,920$ & 0,05 & 1,929 & & & \\
\hline & Sit. conjugal & 14,671 & 0,27 & 1,703 & & & \\
\hline & Escolaridade & $-48,241$ & 0,00 & 1,472 & & & \\
\hline & Religião & $-13,898$ & 0,21 & 1,293 & & & \\
\hline & $\begin{array}{l}\text { Prática } \\
\text { religiosa }\end{array}$ & 9,222 & 0,57 & 1,390 & & & \\
\hline & Comorbidade & $-11,954$ & 0,33 & 1,748 & & & \\
\hline & Hábito de fumo & $-8,561$ & 0,58 & 1,634 & & & \\
\hline & Grau de DPOC & $-0,796$ & 0,97 & 5,083 & & & \\
\hline & Idade & $-0,286$ & 0,65 & 2,004 & & & \\
\hline & IMC & $-1,769$ & 0,16 & 1,867 & & & \\
\hline & Renda per capita & 0,005 & 0,74 & 1,581 & & & \\
\hline & Tempo de DPOC & 1,734 & 0,08 & 1,531 & & & \\
\hline & Anos /maço & 0,013 & 0,94 & 1,778 & & & \\
\hline & VEF $1(\%)$ & $-0,151$ & 0,83 & 4,648 & & & \\
\hline & Escore de BER & 1,031 & 0,22 & 2,489 & & & \\
\hline & Escore de BEE & $-2,717$ & 0,01 & 2,147 & & & \\
\hline \multirow[t]{7}{*}{13} & & & & & $\mathbf{R}^{2}$ & $R^{2}$ aj & DW \\
\hline & Constante & 264,418 & 0,00 & 1,130 & 0,333 & 0,281 & 2,312 \\
\hline & Trabalho atual & $-36,589$ & 0,01 & 1,095 & & & \\
\hline & Escolaridade & $-44,197$ & 0,00 & 1,177 & & & \\
\hline & Comorbidade & $-17,877$ & 0,06 & 1,508 & & & \\
\hline & Escore de BER & 1,301 & 0,04 & 1,481 & & & \\
\hline & Escore de BEE & $-1,938$ & 0,02 & 1,130 & & & \\
\hline
\end{tabular}

Sit. conjugal = situação conjugal; DPOC = Doença Pulmonar Obstrutiva Crônica; IMC = Índice de Massa Corporal; VEF 1 = Volume Expiratório Forçado no primeiro segundo; BER $=$ Bem Estar religioso; BEE $=$ Bem Estar Existencial.

$\mathrm{R}^{2}$ = coeficiente de correlação múltipla, $\mathrm{R}^{2}$ aj =coeficiente de correlação múltipla ajustado, DW = Estatística de Durbin- Watson.

A Tabela 10 mostra que após 13 rodadas, o modelo de regressão para o escore total estabilizou; as variáveis preditoras que permaneceram foram: situação de trabalho atual, escolaridade, presença de comorbidade, escore de BER e escore de BEE. As maiores contribuições para o incremento da QVRS foram das variáveis escolaridade e trabalho atual, diminuindo o escore total em 44 e 36 pontos respectivamente. 
Os valores de VIF indicam que não houve colinearidade, já o valor de $R^{2}$ ajustado indica cerca de $28,1 \%$ da variabilidade é explicada por essas variáveis e a estatística de Durbin - Watson não revelou correlação serial. 


\section{DISCUSSÃO}

Este estudo avaliou a QVRS de pacientes com DPOC e a suas relações com diversas variáveis relacionadas à doença e à características pessoais dos pacientes, incluindo aspectos da espiritualidade, no intuito de ampliar o conhecimento sobre possíveis fatores que influenciam a QVRS desses pacientes. A utilização do Saint George Respiratory Questionnaire e seus componentes permitiu conhecer uma ampla variedade de dados importantes sobre os problemas decorrentes dos sintomas respiratórios, das limitações na atividade física e repercussões da doença na vida diária e no bem estar.

Nos quatro modelos de regressão foram identificados diferentes grupos de variáveis como preditores significantes dos escores obtidos. A escolaridade foi a variável presente em todos os modelos e provou ser um importante fator associado na determinação da QVRS destes pacientes com DPOC.

Os resultados serão discutidos na sequência da sua apresentação, de acordo com os objetivos propostos: descrição da QVRS e análise dos fatores associados, identificados na regressão linear múltipla.

\subsection{FREQUÊNCIA DE RESPOSTAS DOS ITENS DO INSTRUMENTO DE QVRS}

$\mathrm{Na}$ análise individual dos itens do questionário $S G R Q$, alguns se destacaram como de grande importância na avaliação da QVRS.

- a falta de ar foi sentida na maioria dos dias da semana por grande parte dos pacientes durante atividades triviais como tomar banho ou vestir-se, caminhar dentro de casa e subir um lance de escadas e até mesmo quando sentados ou deitados.

- a tosse e a falta de ar faziam com que os pacientes se sentissem exaustos com facilidade, envergonhados e com medo quando não 
conseguiam respirar, desesperançados quanto à melhora da doença e impossibilitados de fazer a maioria das coisas que gostariam.

Miravitlles et al. (2007), no estudo EVOCA, constataram que pacientes em acompanhamento ambulatorial, que sofrem os maiores impactos na qualidade de vida, são àqueles que apresentam tosse e dispneia aos esforços. Estes pacientes apresentam uma maior duração da doença e tomam uma quantidade maior de medicamentos.

Durante a coleta dos dados, os entrevistados relataram um "cansaço constante" e a maior parte deles queixava-se de falta de ar para realizar atividades muito simples, como contar uma história, arrumar a casa ou fazer compras, por exemplo; além disso, a dependência da ajuda de amigos e familiares, a impossibilidade de trabalhar e o constante medo de uma exacerbação que os levasse a "morrer por falta de ar", fazia com que muitos não sentissem mais prazer na vida.

- As exacerbações foram um fenômeno presente nesta amostra, podendo estender - se em até mais de uma semana de desconforto.

Os pacientes com DPOC experimentam períodos de estabilidade clínica, pontuados por episódios agudos sintomáticos que são distintos da variação diária dos sintomas, as exacerbações. Estudos que examinam a associação entre exacerbações e QVRS demonstram correlação com o decréscimo na função pulmonar, aumento dos custos com o tratamento, aumento da mortalidade e em especial, um impacto negativo e muitas vezes permanente na QVRS (Esteban et al., 2009).

Nesta amostra pudemos observar alguns destes aspectos: $67,1 \%$ apresentaram exacerbações, destes $48,9 \%$ permaneceram em crise por mais de uma semana; os pacientes apresentaram uma má função pulmonar, com valores abaixo de $50 \%$ do previsto e altos escores no SGRQ, indicativos de uma má QVRS. Foi frequente no relato dos pacientes que as internações, ou idas ao pronto socorro, por conta das crises, deixavam "cicatrizes" , "sequelas" e ainda, que após esses períodos, eles "nunca mais voltavam ao que eram antes".

- Uma parcela significativa da amostra declarou ter medo quando não consegue respirar. 
Em entrevista, 78,6\% dos pacientes relataram que sentem-se com medo quando apresentam dispneia, muitos deles comentavam que quando apresentavam uma sensação de falta de ar mais intensa, passava-lhes pela mente que àquela poderia ser a última e que isto Ihes causava uma angústia muito grande.

\subsection{AVALIAÇÃO DA QUALIDADE DE VIDA RELACIONADA À SAÚDE}

Os valores médios dos escores do SGRQ foram os seguintes: 65 para sintomas, 72 para atividade, 57 para impactos e 63 para escore total. Estes valores indicam uma má qualidade de vida, uma vez que quanto maior o escore, menor é a medida de QVRS.

Comparativamente aos outros estudos, os escores desta amostra sugerem uma pior QVRS em relação aos demais, apesar da semelhança nas características de idade, anos/maço, VEF1 e classificação GOLD de gravidade da DPOC. Uma exceção pode ser observada no estudo de Ansari et al (2007), com pacientes da região nordeste da Inglaterra, em que dados para sintomas (67), atividade (83), impactos (56) e total (66) aproximam-se dos encontrados no presente estudo, sendo os mais altos na literatura revisada. Os melhores valores de QVRS foram os encontrados por Torres (2006), em estudo no hospital universitário de Nossa Senhora da Candelária, na Espanha: sintomas = 39 , atividade $=37$, impactos $=15$ e total $=26$.

Observando os dois estudos que obtiveram valores opostos, os dados sóciodemográficos e clínicos apresentados são muito similares (frequências de sexo, faixa etária, hábito de fumo, carga tabágica, VEF1 e estadio GOLD), o que leva a supor que outros fatores estivessem envolvidos na determinação da QVRS dos pacientes estudados.

No presente estudo, 17 variáveis foram incluídas na análise multivariada (sexo, trabalho atual, situação conjugal, escolaridade, religião, ter prática religiosa, presença de comorbidades, hábito de fumo, grau de DPOC, idade, IMC, renda per capita, tempo de DPOC, anos/maço, VEF1, bem estar religioso 
e existencial). Sete delas foram capazes de influenciar nos escores do SGRQ (escolaridade, tempo de DPOC, trabalho atual, comorbidade, BER, BEE e anos/ maço), sendo a variável escolaridade a mais frequente e de maior influência, seguida pela trabalho atual.

A variável escolaridade, incluída na regressão de forma dicotômica (alfabetizado e não alfabetizado), foi fator independentemente associado aos domínios Sintomas $(\beta-15,152)$ Atividade $(\beta-10,753)$ Impactos $(\beta-19,326)$ e escore total $(\beta-44,197)$. Estes dados indicam que o fato de o paciente ser alfabetizado diminui significativamente todos os aspectos da QVRS, avaliados pelo instrumento $S G R Q$, ou seja, corresponde a uma melhor qualidade de vida. O baixo grau de instrução pode limitar e muito o acesso a informações, a busca e o entendimento da doença/tratamento. Entre os pacientes deste estudo, $15,5 \%$ declararam-se analfabetos, mas esse número pode ser muito maior quando se considera o analfabetismo funcional, ou seja, indivíduos que possuem a capacidade de decodificar minimamente as letras, geralmente frases, sentenças e números, mas ainda não desenvolveram a habilidade de interpretação de textos. Durante a coleta de dados pode-se perceber que, mesmo àqueles que declaravam ter estudado até o nível fundamental (65,7\%), apresentavam grande dificuldade no preenchimento de seus dados no Termo de Consentimento e a linguagem de alguns itens dos questionários os deixavam confusos.

Entre os estudos levantados, poucos divulgaram dados sobre o nível educacional de suas amostras: Garrido et al. (2006), utilizando dados do estudo multicêntrico espanhol EPIDEPOC, obteve como resultados, 20,5\% dos entrevistados sem estudo formal, 56,7\% com estudo primário, 17,5\% com estudo secundário e 5,2\% com estudo universitário; Kühl, Schürmann, Rief (2008), utilizaram amostra de uma clínica particular especializada em pneumologia e encontraram $76,9 \%$ dos pacientes com menos de 9 anos de estudo formal, 13,3\% com 10 e 9,8\% com 13 anos; Moy et al. (2009), obtiveram no estudo NETT, valores indicativos para escolaridade de $80 \%$ dos entrevistados com o colegial completo ou ensino superior.

Dois destes estudos (Garrido et al.,2006; Moy et al., 2009) estudaram a escolaridade como variável no modelo de regressão para analisar se esta se 
comportava como uma preditora de qualidade de vida, ambos estudos encontraram que a escolaridade influencia no aumento da qualidade de vida, em seu componente físico, medido pelo questionário SF-12, corroborando com os dados encontrados em nosso estudo.

Destacamos, ainda, estudos cujos objetivos eram avaliar o impacto dos fatores socioeconômicos (incluindo a escolaridade) no desenvolvimento e manifestações da DPOC: Kanervisto et al (2011) e Eisner et al (2011). Kanervisto et al (2011) utilizou uma amostra de 8028 pessoas, na Finlândia, a fim de buscar associações entre educação e outro fatores socioeconômicos e a manifestação de doenças pulmonares obstrutivas, obtendo como resultado o nível educacional básico como fator de risco para desenvolvimento da DPOC em ambos os gêneros; Já Eisner et al (2011) conduzindo o estudo FLOW, encontrou relações entre a baixa escolaridade e maiores escores de gravidade da DPOC e BODE, piores valores de FEV 1, maior grau de obstrução, menor distância alcançada no TC6, menor função das extremidades dos membros, aumento do risco de exacerbações e piora da qualidade de vida.

A variável tempo de DPOC apareceu como fator associado no domínio Sintomas, mas acrescentando um baixo valor à piora da qualidade de vida. Isto talvez se explique pelo fato de que os pacientes se adaptam aos sintomas da doença ao longo do tempo e apenas percebam o seu impacto quando ocorre um aumento da sua frequência ou da intensidade.

Miravitlles et al. (2007) encontrou dados semelhantes aos nossos em relação ao tempo de DPOC, onde a correlação com a QVRS medida pelo SGRQ foi positiva, porém de pequena contribuição.

A variável trabalho atual foi um fator significativamente associado ao domínio Atividade ( $\beta-12,215$ ) e ao escore total do SGRQ ( $\beta-44,197$ ), proporcionando melhoria na QVRS. Para uma amostra com tão baixo nível de renda (renda mensal per capita de $\mathrm{R} \$ 486$ ), ter um trabalho foi importante para os pacientes, pois, além de contribuir para um ganho nas condições de vida, também traz satisfação, proporcionando um incremento na QVRS.

Cleland, Lee, Hall (2007), utilizaram amostra de 110 pacientes em atendimento primário no Reino Unido, e encontraram valores semelhantes aos nosso quanto a situação de trabalho (apenas 18,4\% empregados); os autores 
realizaram regressão logística, e encontraram relações de aumento do risco para desenvolvimento de ansiedade e depressão em pacientes com DPOC sem trabalho atual.

Eisner et al (2011) obtiveram resultados que sustentam nossos achados quanto às variáveis escolaridade e trabalho atual: a baixa renda combinada à baixa escolaridade, influenciaram todos os domínios mensurados em seu estudo. Os autores inferem que estes pacientes sofrem com maiores obstáculos na busca e obtenção de tratamento adequado, desde o diagnóstico ser realizado mais tardiamente, até o fato de possuírem poucos mecanismos de suporte social (longas distâncias a serem percorridas na busca de um serviço de saúde, pouca flexibilidade no trabalho, baixa disponibilidade de farmácias nas proximidades e eficácia na comunicação entre paciente e agente de saúde).

A presença de comorbidades apareceu como fator associado ao domínio Atividade $(\beta-8,996)$ e ao escore total $(\beta-17,877)$ e a variável anos-maço, ao domínio Impacto $(\beta-0,131)$.

Garrido et al. (2006); Berry , Adair, Rejeski (2010); Bliderman et al. (2008) e Esteban et al. (2009) incluíram dados sobre a presença de comorbidades entre os pacientes com DPOC, este último, incluiu a variável no estudo dos determinantes da QVRS, e obteve como resultado um valor de $\beta$ aproximado 1,638 de incremento no escore total do SGRQ.

Diversos estudos divulgaram valores para a variável anos/maço (Torres et al., 2006; Ansari et al., 2007; Moy et al., 2009; Yaksic et al.,2003; Ying-Xiang et al.,2009; Berry, Adair, Rejeski, 2006; Esteban et al.,2009; Fracés et al., 2008; Nunes et al., 2009; Miravitlles et al, 2007), em três deles ela foi estudada como fator associado a QVRS: Miravitlles et al (2007), utilizaram estatística odds ratio e encontraram valor de 0,991; Nunes et al. (2009) obtiveram valores de correlação, $r$ 0,16 com o SGRQ total, $r$ 0,39 no domínio sintomas, $r$ 0,13 em atividades e 0,07 em impactos, já Francés et al., (2008) encontraram correlação r 0,24 com o SGRQ total e r 0,33 com o domínio sintomas. Analisando estes, estudos, apesar de haver uma relação causal entre o consumo do tabaco e o desenvolvimento da doença, ainda não há um consenso sobre se há uma 
contribuição significativa desta variável na diminuição da QVRS dos pacientes já portadores de DPOC.

As variáveis que medem o bem estar espiritual estiveram presentes e foram fatores associados ao domínio Atividade (BER - $\beta=0,4$; $B E E-\beta=-0,8$ ) e ao escore total (BER - $\beta=1,3$; BEE $-\beta=-2$ ). Apesar do pequeno impacto na variação dos escores, estes dados sugerem que estes componentes do bemestar espiritual têm influência positiva sobre a QVRS dos pacientes, considerando que uma diminuição nos escores representa uma melhor percepção de QVRS.

Em estudo anterior com essa mesma amostra, Silva et al (2009) analisaram as relações entre as dimensões do Seattle Obstructive Lung Disease Questionnaire e o bem-estar espiritual. Os resultados já sugeriam que um maior grau de incapacidade física decorrente da DPOC estava relacionado a maior envolvimento com crenças e práticas religiosas.

Muitos dos pacientes informaram ser membros ativos de igrejas e que frequentavam regularmente as missas e cultos. A maior influência do componente religioso no escore total de QVRS talvez possa ser explicada pela importância dada a essas atividades.

Ressaltamos que a baixa contribuição das variáveis de bem estar espiritual no escore final de QVRS, medida pelo SGRQ, possa ser atribuída pela própria proposta/constituição do instrumento. O SGRQ foi desenhado e validado para medir três domínios: sintomas, atividade e impacto, compostos por questões bastante objetivas sobre a rotina e sintomas apresentados pelos entrevistados; são escassas questões que remetam ao sentimento do paciente em relação à doença ou mecanismos de coping. Silva et al (2009) puderam observar outros aspectos da QVRS medidos pelo SOLDQ (satisfação com o tratamento, função emocional e habilidade de coping) e obtiveram uma correlação maior entre as variáveis de bem estar espiritual e a QVRS; acreditamos que esse fato se deu em função da proposta de medida do questionário.

Espiritualidade e religiosidade são temas de interesse crescente na área da saúde e têm sido extensivamente reconhecidas como importantes recursos internos que ajudam a enfrentar as adversidades do dia-a-dia e os eventos 
traumáticos e estressantes, proporcionado melhorias na qualidade de vida (Panzini et al, 2007).

Quanto ao coeficiente de correlação múltipla, os modelos de regressão utilizados responderam a $10,3 \%$ da variabilidade no domínio sintomas, $24,5 \%$ em atividade, $20,4 \%$ em impactos e $28,1 \%$ no escore total do SGRQ. As estatísticas que verificam multicolinearidade e correlação serial não acusaram interferências em nenhum dos modelos.

Diante das inúmeras repercussões da DPOC, é necessário aprofundar a compreensão do maior número possível de fatores que os pacientes relatam como sendo importantes para a sua qualidade de vida, a fim de buscar estratégias que possam, de fato, melhorar o bem estar dos pacientes. Esses fatores são múltiplos, interagem de forma complexa e vão muito além dos parâmetros físicos e fisiológicos utilizados nas avaliações funcionais, o que reforça a constatação de que as intervenções que visam à melhora da função respiratória, por si sós, não dão conta de atender as necessidades dos pacientes.

\section{CONCLUSÕES}


Os resultados deste estudo permitiram concluir que a limitação das atividades físicas contribuiu para o maior prejuízo na QVRS, seguida pelos sintomas da doença e do seu impacto psicossocial.

Foram analisados quatro modelos de regressão para o escore total do SGRQ e os seus três domínios. Cinco variáveis explicaram $28 \%$ da variância do escore total e $24,5 \%$ do escore de Atividade: escolaridade, trabalho, presença de comorbidade, bem-estar religioso e bem-estar existencial.

Ser alfabetizado foi o fator presente e de maior influência positiva em todos os domínios e no escore total de QVRS. 
Alguns aspectos referentes às limitações deste estudo são apontadas a seguir.

- A amostra foi composta por um número relativamente reduzido de pacientes, selecionados por conveniência, o que não garante a representatividade da população. Além disso, o estudo foi realizado num único serviço, um ambulatório especializado em doenças respiratórias que é considerado referência no atendimento de casos mais graves. Esta característica do local da pesquisa refletiu na composição de uma amostra com pouca variação nos níveis de gravidade da DPOC, concentrando cerca de $70 \%$ de pacientes graves ou muito graves .

- O desenho transversal do estudo não permite estabelecer relação temporal ou causal entre as variáveis exploradas e a QVRS.

- Na estratégia de regressão múltipla, um número menor de variáveis poderia ter aumentado a precisão das análises realizadas.

- Outro aspecto a ser considerado refere-se a um possível viés de informação no que se refere às questões do domínio Sintomas do SGRQ. É difícil afirmar até que ponto as respostas sobre detalhes de eventos ocorridos "durante o último ano" antes da entrevista não tenham sido influenciadas por fatos mais recentes ou por aqueles que foram mais facilmente lembrados.

- A aplicação do instrumento SGRQ em combinação com uma medida de QV geral, como por exemplo, o WHOQO-bref, poderia ampliar o perspectivas de análise e o conhecimento acerca da qualidade de vida dos pacientes estudados. Outras medidas relacionadas à saúde mental, como as de ansiedade ou depressão, também poderiam ser incluídas.

Apesar dessas limitações, os resultados do estudo trazem informações relevantes sobre aspectos ainda pouco explorados, como a espiritualidade, fornecendo subsídios para o atendimento das diversas necessidades dos pacientes e indicando caminhos para o desenvolvimento de novos estudos sobre a QVRS de pacientes com DPOC.

\section{REFERÊNCIAS}


Ansari K, Shamssain M, Keaney NP, Burns G, Farrow M. Predictors of quality of life in chronic obstructive pulmonary disease patients with different frequency of exacerbations. Pak J Med Sci 2007; 23 (4): 490-6.

Bauldoff RN, Diaz PT. Improving outcomes for COPD patients. The nurse practitioner 2006; 31(8): 27-43.

Bekelman DB, Dy SM, Becker DM, Wittstein IS, Hendricks DE, Yamashita TE et al., Spiritual well-being and depression in patients with heart failure. Society of General Internal Medicine 2007; 22: 470-77

Berry MJ, Adair NE, Rejeski WJ. Use of Peak Oxygen Consumption in Predicting Physical Function and Quality of Life in COPD Patients. Chest 2006;129;1516-1522

Blinderman CD, Homel MAP, Billings A, Tennstedt, Portenoy RK. Symptom distress and quality of life in patients with advanced chronic obstructive pulmonary disease. Journal of Pain and Symptom Management 2009; 38(1): 115-123

Camelier AA. Avaliação da qualidade de vida relacionada à saúde em pacientes com DPOC: estudo de base populacional com SF12 na cidade de São PauloSP. Tese. São Paulo (SP): Universidade Federal de São Paulo; 2004.

Cleland JA, Lee AJ, Hall S. Associations of depression and anxiety with gender, age, health- related quality of life and symptoms in primary care COPD patients. Family Practice 2007; 24: 217-223.

Costa CC Bastiani M Geyer JG, Calvetti PU, MullerMC, Moraes MLA. Qualidade de vida e bem-estar espiritual em universitários de psicologia. Psicologia em Estudo, Maringá 2008; 13(2):249-255

Curtis JR, Patrick DL. The assessment of health status among patients with COPD. Eur Respir J. 2003;41:36S-45S.

Cully JA, Graham DP, Stanley MA, Ferguson CJ, Sharafkhaneh A, Souchek J, KUNIK ME. Quality of Life in Patients With Chronic Obstructive Pulmonary Disease and Comorbid Anxiety or Depression. Psychosomatics ; 47: 4.

Decramer M, Benedetto FD, Ponte AD, Marinari S. Systemic effects of COPD. Respiratory Medicine 2005; 99: S3-S10.

Dourado VZ, Carvalho LR, Godoy I. Influência de características gerais na qualidade de vida de pacientes com doença pulmonar obstrutiva crônica. Jornal Brasileiro de Pneumologia 2004; 30(2): 207-14.

Dourado VZ, Antunes LCO, Tanni SE, Godoy I. Fatores associados à diferença clinicamente significativa da qualidade de vida relacionada à saúde após 
condicionamento físico em pacientes com DPOC. Jornal Brasileiro de Pneumologia 2009;35(9):846-853

Eisner MD, Blanc PD, Omachi TA, Yelin EH, Sidney S, Katz PP, Ackerson LM, Sanchez G, Tolstykh I, Iribarren C. Socioeconomic status, race and COPD health Outcomes. J epidemiol Community Health 2011; 65: 26-34

Esteban C, Quintana JM, Moraza J, Aburto M, Egurrola M, España PP, Pérez-Izquierdo J, Aguirre U, Aizpiri S, Capelastegui A. Impact of hospitalisations for exacerbations of COPD on health-related quality of life.

Repiratory medicine 2009; 103: 1201-1208

Evans DR. Enhancing quality of life in the population at large. In: Romney DM, Brown RI, Fry PS (ed). Improving the quality of life. Recommendations for people with and without disabilities. Dordrecht, Boston, London, Kluwer Academic Pub., 1994.

Ferrer M ,Villasante C, Alonso J, Sobradillo V, Gabriel R, Vilagut G, Masa JF, Viejo JL, Jimenez-Rui CA, Miravitlles M. Interpretation of quality of life scores from the St George Respiratory Questionnaire. European Respiratory Journal 2002; 19: 405-413.

Fleck MPA, Leal O, Louzada S, Xavier M, Chachamovich E, Vieira G, Santos L, Pinzon V. Desenvolvimento da versão em português do instrumento de avaliação de qualidade de vida da OMS (WHOQOL-100). Revista Brasileira de Psiquiatria 1999; 21 (1): 19-28.

Fleck MPA, Louzada S, Xavier M, Chachamovich E, Vieira G, Santos L, Pinzon V.. Aplicação da versão em português do instrumento abreviado de avaliação de qualidade de vida "WHOQOL-bref". Revista de Saúde Pública 2000; 33 (2): 178-183.

Francés MEM, Tordera MP, Fuster AB, Moragón EMM, Torrero LC. Impact of Baseline and Induced Dyspnea on the Quality of Life of Patients With COPD. Arch Bronconeumol. 2008;44(3):127-34

Garratt AM, Schmidt L, Mackintosh A, Fitzpatrick R. Quality of life measurement: bibliografic study of patients assessed health outcomes measures. BMJ 2002; 324: 1417-32.

Garrido PC, Díez JM, Gutiérrez JR, Centeno AM, Vázquez EG, Miguel AG, Carballo MG, García RJ. Negative impact of chronic obstructive pulmonary disease on the health-related quality of life of patients. Results of the EPIDEPOC study. Health and Quality of Life Outcomes 2006, 4:31

Gastaud MB, Souza LDM, Braga L, Horta LH, Oliveira FM, Sousa PLR, Silva RA. Bem estar espiritual e transtornos psiquiátricos menores em estudantes de Psicologia: estudo transversal. Revista de Psiquiatria do RS 2006;28(1):12-18. 
Gill TM, Feinstein AR. A critical appraisal of the quality of quality-of-life measurements. JAMA 1994; 272(8): 619-26.

Global Initiative for Chronic Obstructive Lung Disease (GOLD). Global Strategy for Diagnosis, Management and Prevention of Chronic Obstructive Pulmonary Disease. NHLBI/ WHO workshop report. Executive summary 2007.

Guimarães HP, Avezum A. O impacto da espiritualidade na saúde física. Rev Psiq Clin 2007;34, supl 1:88-94.

Hair Jr JF, Anderson RE, Tatham RL, Black WC. Análise multivariada dos dados. Porto Alegre, Artmed, 5ª edição, 2005.

Haughney J, Gruffydd-Jones K. Patient-centred outcomes in primary care management of COPD — what do recent clinical trial data tell us? Primary Care Respiratory Journal 2004; 13, 185-97.

$\mathrm{Hu} \mathrm{J}$, Meek $\mathrm{P}$. Health related quality of life in individuals with chronic obstructive pulmonary disease. Heart and Lung 2005; 34 (6): 415-422.

Hulley SB, Cummings SR, Browner WS, Grady D, Newman TB. Delineando a pesquisa clínica: uma abordagem epidemiológica. Artmed, Porto Alegre, $3^{a}$ edição, 2008.

Jenkins C, Rodriguez-Roisin R. Quality of life, stage severity and COPD. European Respiratory Journal 2009; 33:953-955.

Jones PW, Quirk FH, Baveystock CM, Lit- tlejohns P. A self-complete measure of health status for self-complete measure of health status for chronic airflow limitation. The St. George's Respiratory Questionnaire. Am Rev Respir Dis. 1992;145:1321-1327.

Jones P, Lareau S, Mahler D. Measuring the effects of COPD on the patient. Respiratory Medicine 2005; 99, s11-s18.

Jones PW, Forde Y. St George's Respiratory Questionnaire Manual. St George's, University of London, Division of Cardiac and Vascular Science. Version 2.2 [updated 2008 Mar; cited 2010 Jan 08]. Available from: http://www.healthstatus.sgul.ac.uk/SGRQ_download/SGRQ\%20Manual.pdf

Kanervisto M, Vasankari T, Laitinen T, Heliovaara M, Jousilahti P, Saarelainen S. Low socioeconomic status is associeated with chronic obstructive airway diseases. Respiratory Medicine (2011) xx, 1-7

Katsura H, Yamada K, Kida K. Both generic and disease specific health-related quality of life are deteriorated in patients with underweight COPD. Respiratory Medicine 2005; 99 (5): 624-30. 
Kerkoski E, Borenstein MS, Gonçalves LO, Francionu FF. Grupo de convivência com pessoas com doença pulmonar obstrutiva crônica: sentimentos e expectativas. Texto e Contexto de Enfermagem, 2007; 16(2):225-32.

King CR, Hinds PS (ed.). Quality of life from nursing and patient perspectives: theory, research and practice. Sandbury, MA: Jones and Bartlett Publishers, 1998. p: xi.

Ko B, Khurana A, Spencer J, Scott B, Hahn M, Hammes M. Religious beliefs and quality of life in an American inner-city hemodialysis population. Nephrology Dialysis Transplantations (2007) 22: 2985-2990.

Kohler CL, Fish L, Greene PG. The relationship of perceived self - efficacy to quality of life in chronic obstructive pulmonary disease. Health Psychology 2002; 21(6):610-14.

Koff PB, Jones RH, Cashman JM, Voelkel NF, Vandivier RW. Proactive integrated care improves quality of life in patients with COPD. European Respiratory Journal 2009; 33: 1031-1038.

Kühl K, Schürmann W, Rief W. Mental disorders and quality of life in COPD patients and their spouses. International Journal of COPD 2008:3(4) 727-736

Mahler DA. How Should Health-Related Quality of Life be assessed in patients with COPD? Chest 2000; 117:54S-57S.

Mangueira NM, Viega IL, Mangueira MAMM, Pinheiro AN, Costa MRSR. Correlação entre parâmetros clínicos e qualidade de vida relacionada à saúde em mulheres com DPOC. Jornal Brasileiro de Pneumologia 2009;35(3):248255.

Marques LF. A saúde e o bem-estar espiritual em adultos portoalegrenses.Psicologia Ciência e Profissão 2003; 23(2): 56-65.

Marques LF, Sarriera JC, Dell'Aglio DD. Adaptação e validação da escala de bem-estar espiritual (EBE). Avaliação Psicológica, 2009, 8(2), pp. 179-186

Maurer J, Rebbapragada V, Borson S, Goldstein R, Kunik ME, Yohannes AM, Nicola A. Hanania NA. Anxiety and Depression in COPD - current understanding, unanswered questions, and research needs. CHEST 2008; 134:43S-56S.

Menezes AMB, Jardim JR, Pérez-Padilha R, Camelier A. Rosa F, Nascimento $\mathrm{O}$, Hallal PC. Prevalence of chronic obstructive pulmonary disease and associated factors: the PLATINO Study in Sao Paulo, Brazil. Cad Saude Publica. 2005; 21(5):1565-73.

Minayo MC, Hartz ZM, Buss PM. Qualidade de vida e saúde: um debate necessário. Ciênc Saúde Coletiva. 2000;5(1):7-18. 
Miravitlles M, Molina J, Naberan K, Cots JM, Ros F e Llor C. Factors determining the quality of life of patients with COPD in primary care. Therapeutic Advances in Respiratory Disease 2007; 1(2): 85-92.

Moreira-Almeida A, Lotufo-Neto F, Koenig HG. Religiousness and mental health: a review. Rev Bras Psiquiatr. 2006;28(3):242-50.

Moy ML, Reilly JJ, Ries AL, Mosenifar Z, Kaplan RM, Lew R, Garshick E. Multivariate models of determinants of health-related quality of life in severe chronic obstructive pulmonary disease. Journal of rehabilitation research and development 2009; 46(5): 643-654.

Nunes DM, Mota RMS, Neto OLP, Pereira EDB, Bruin VMS, Bruin PFC. Impaired Sleep Reduces Quality of Life in Chronic Obstructive Pulmonary Disease. Lung 2009;187:159-163.

Oliveira FB, Vale RG, Guimarães FS, Batista LA, Dantas EHM. Efeitos do grau de DPOC sobre a qualidade de vida de idosos. Fisioterapia em movimento 2009;22(1):87-93

Panzini RG, Rocha NS, Bandeira DR, Fleck MPAF. Qualidade de vida e espiritualidade. Rev Psiq Clin. 2007; 34(sup.1):105-15.

Pimentel FL. Qualidade de vida em oncologia. Coimbra: Almedina, 2006, 206p.

Rennard SI. Inflammation in COPD: a link to systemic comorbidities. Eur Respir Rev 2007; 16 (105): 91-97.

Rodrìguez-Rosero JE, Ferriani MGC, Dela Coleta MF. Escala de locus de controle da sa'de - MHLC: estudos de validaÁ,o. Revista Latino Americana de Enfermagem 2002; 10(2):179-84.

Sant'Anna CA, Stelmach R, Zanetti Feltrim MI, Filho WJ, Chiba T, Cukier A. Evaluation of health-related quality of life in low-income patients with COPD receiving long-term oxygen therapy. Chest. 2003;123(1):136-41.

Sanches FF, Faganello MM, Tanni SE, Lucheta PA, Padovani CR, Godoy I. Relationship between disease severity and quality of life in patients with chronic obstructive pulmonary disease. Braz J Med Biol Res. 2008; 41(10): 860-5.

Scientific Advisory Committee of the Medical Outcomes Trust. Assessing health status and quality-of-life instruments: Attributes and review criteria. Quality of Life Research 2002; 11: 193-205. 
Shackell BS, Jones RCM, Harding G, Pearse S, Campbell J. "Am I going to see the next morning?' A qualitative study of patients perspectives of sleep in COPD. Primary Care Respiratory Journal 2007; 16(6): 378-383

Silva MS, Kimura M, Stelmach R, Santos VLCG. Qualidade de vida e bem-estar espiritual em pacientes com doença pulmonar obstrutiva crônica. Rev Esc Enferm USP 2009; 43(Esp 2):1187-92

Souza TC, Jardim JRB, Jones P. Validação do questionário do hospital Saint George na Doença Respiratória (SGRQ) em pacientes portadores de doença pulmonar obstrutiva crônica no Brasil. Jornal de Pneumologia 2000;16: 119125.

Testa MA, Simonson DC. Assessment of quality-of-life outcomes. New England Journal of Medicine1996; 334 (13): 835-40.

Tomas LHS, Varkey B. Improving health related quality of life in chronic obstructive pulmonary disease. Current Opinion in Pulmonary Medicine 2004; 10: 120-127.

Torres JP, Casanova C, Hernández C, Abreu J, Garcini AM, Aguirre-Jaime A, Celli BR. Gender associated differences in determinants of quality of life in patients with COPD: a case series study. Health and Quality of Life Outcomes 2006, 4:72

Tze-Pin Ng, Niti M, Wan-Cheng T, Zhenying C, Kian-Chung O, Philip Eng. Depressive Symptoms and Chronic Obstructive Pulmonary Disease: Effect on Mortality, Hospital Readmission, Symptom Burden, Functional Status, and Quality of Life. Arch Intern Med. 2007;167:60-6

Vogelsang G, Brahmer, JR. Patient-reported outcomes and managed care decisions: Quality of life and related components. The Am J Manag Care. 2002 Dec; 8 (18 Suppl.): S548-S549.

Volcan SM, Sousa PL, Mari JJ, Horta B. Relação entre bem-estar espiritual e transtornos psiquiátricos menores: estudo transversal. Revista de Saúde Pública. 2003; 37 (4): 440-5.

Voll-Aanerud M, Eagan TML, Wentzel-Larsen T, Gulsvik A, Bakke PS. Respiratory symptoms, COPD severity and health related quality of life in a general population sample. Respiratory Medicine 2008; 102: 399-406.

Yaksic MS, Tojo M, Cukier A, Stelmach R. Profile of a Brazilian population with severe chronic obstructive pulmonary disease. Jornal de Pneumologia 2003;29(2):64-8

Ying-xiang L, Wan-ning X, Li-rong L, Bao-sen P, Xiu-hong N, Hong ZJW, Yuxiang $L$, Dan-qi $W$, Zhen-yang $X$, Hong-wu W, Hu-sheng $Z$, Zheng-yi $H$, Ting $Y$, Chen $W$. The cross-sectional and longitudinal association of the BODE index 
with quality of life in patients with chronic obstructive pulmonary disease. Chinese Medical Journal 2009;122(24):2939-2944 


\section{APÊNDICES}

APÊNDICE A 
TERMO DE CONSENTIMENTO LIVRE E ESCLARECIDO

\section{I - DADOS DE IDENTIFICAÇÃO DO SUJEITO DA PESQUISA OU RESPONSÁVEL LEGAL}

1.NOME.

DOCUMENTO DE IDENTIDADE No : SEXO : .M F

DATA NASCIMENTO: .......................

ENDEREÇO

BAIRRO

CEP: TELEFONE: DDD C.......... $N$

APTO: CIDADE

2.RESPONSÁVEL LEGAL

NATUREZA (grau de parentesco, tutor, curador etc.) DOCUMENTO DE IDENTIDADE : SEXO: M F DATA NASCIMENTO.: ..................... ENDEREÇO: BAIRRO:.

CEP: CIDADE: $N^{0}$. APTO: TELEFONE:DDD(.

.).

\section{II - DADOS SOBRE A PESQUISA CIENTÍFICA}

1. TÍTULO DO PROTOCOLO DE PESQUISA : “Qualidade de Vida relacionada à saúde em Pacientes com Doença Pulmonar Obstrutiva Crônica"

PESQUISADOR: Maíra Shiramizu da Silva

$$
\text { Rafael Stelmach (responsável) }
$$

CARGO/FUNÇÃO: Médico Assistente 53505

INSCRIÇÃO CONSELHO REGIONAL N

UNIDADE DO HCFMUSP: Pneumologia

3. AVALIAÇÃO DO RISCO DA PESQUISA:

$\begin{array}{lll}\text { SEM RISCO } & X & \text { RISCO MÍNIMO } \\ \text { RISCO BAIXO } & \text { RISCO MAIOR }\end{array}$

(probabilidade de que o indivíduo sofra algum dano como conseqüência imediata ou tardia do estudo) 4.DURAÇÃO DA PESQUISA : Previsão para coleta de dados : novembro/2007 a abril/2008.

\footnotetext{
III - REGISTRO DAS EXPLICAÇÕES DO PESQUISADOR AO PACIENTE OU SEU REPRESENTANTE LEGAL SOBRE A PESQUISA CONSIGNANDO:
} 
As pessoas com DPOC costumam apresentar problemas como falta de ar, tosse, dificuldade para fazer atividades físicas, dependência dos familiares, ansiedade. Tudo isso causa uma série de limitações e repercussões na vida diária que podem comprometer a sua qualidade de vida.

Nos últimos anos, os profissionais de saúde têm se interessado em estudar como a doença, os sintomas e o seu tratamento afetam a vida das pessoas.

Em situações difíceis da vida, como no caso de doenças, algumas pessoas tendem a buscar apoio nas suas crenças e práticas religiosas e espirituais, para aliviar o estresse e as preocupações e manter a esperança para enfrentar a situação.

Queremos fazer um estudo para saber o que pacientes com DPOC acham da sua qualidade de vida e se a parte espiritual tem alguma influência na qualidade de vida.

Para tanto, faremos uma entrevista na qual utilizaremos alguns questionários que avaliam aspectos da espiritualidade e da qualidade de vida das pessoas. Nessa pesquisa não será realizado nenhum tipo de intervenção ou tratamento. As informações serão obtidas através das respostas dos questionários utilizados.

Se, por qualquer motivo, o(a) sr(a) resolver não continuar a responder os questionários, não haverá prejuízo para o tratamento de seu problema de saúde. Se em algum momento, o(a) $\operatorname{sr}(a)$ nã quiser mais participar da pesquisa, qualquer que seja o motivo, sua vontade será respeitada.

Em caso de dúvidas ou perguntas relativas ao estudo ou aos direitos relativos à participação neste estudo, poderá ser contatada a pesquisadora que acompanha diretamente o estudo, Maíra Shiramizu da Silva e/ou o responsável pelo estudo, Dr. Rafael Stelmach.

\section{IV - ESCLARECIMENTOS DADOS PELO PESQUISADOR SOBRE GARANTIAS DO SUJEITO DA PESQUISA CONSIGNANDO:}

$\mathrm{O} \operatorname{Sr}(\mathrm{a})$ :

1. terá acesso a qualquer tempo, às informações sobre procedimentos, riscos, e benefícios relacionados à pesquisa, inclusive para esclarecer eventuais dúvidas.

2. terá liberdade de retirar seu consentimento a qualquer momento e de deixar de participar do estudo, sem que isso traga prejuízo à continuidade da assistência.

3. terá garantido que todas as informações fornecidas serão consideradas confidenciais, sigilosas e privativas. Nos resultados da pesquisa não será divulgado nenhum nome ou outra forma de identificação dos participantes.

\section{INFORMAÇÕES DE NOMES, ENDEREÇOS E TELEFONES DOS RESPONSÁVEIS PELO ACOMPANHAMENTO DA PESQUISA, PARA CONTATO EM CASO DE INTERCORRÊNCIAS CLÍNICAS E REAÇÕES ADVERSAS.}

Pesquisadora

Maíra Shiramizu da Silva

Rafael Stelmach (responsável) tel: 3663-1723 e-mail: mai@usp.br

3069-5034～pnerafael@incor.usp.br

pneumologia

End: Av. Dr. Enéas de Carvalho Aguiar, $444^{\circ}$ andar, serviço de 


\section{VI - CONSENTIMENTO PÓS-ESCLARECIDO}

Acredito ter sido suficientemente informado a respeito das informações que li ou que foram lidas para mim, descrevendo o estudo "Qualidade de vida e bem-estar espiritual em pacientes com doença pulmonar obstrutiva crônica". Eu discuti com Maíra Shiramizu da Silva sobre a minha decisão em participar nesse estudo. Ficaram claros para mim quais são os propósitos do estudo, os procedimentos a serem realizados, seus desconfortos e riscos, as garantias de confidencialidade e de esclarecimentos permanentes. Ficou claro também que minha participação é isenta de despesas e que tenho garantia do acesso a tratamento hospitalar quando necessário. Concordo voluntariamente em participar deste estudo e poderei retirar o meu consentimento a qualquer momento, antes ou durante o mesmo, sem penalidades ou prejuízo ou perda de qualquer benefício que eu possa ter adquirido, ou no meu atendimento neste Serviço.

Assinatura do paciente/representante legal

Data 11

Declaro que obtive de forma apropriada e voluntária o Consentimento Livre e Esclarecido deste paciente ou representante legal para a participação neste estudo.

Assinatura do responsável pelo estudo

Data

11

\section{APÊNDICE B}




\section{Instrumento de Caracterização Sociodemográfica e Clínica}

$\mathbf{N}^{\mathrm{o}}$

Nome (iniciais): RGHC:

- Sexo: 1.( ) Masculino 2.( ) Feminino

- Data de nascimento:

- Peso Altura IMC

- Trabalha atualmente: 1. ( ) Não ～2. ( ) Sim

- Renda mensal individual Renda mensal familiar

- Número de pessoas que dependem da renda:

- Situação conjugal: 1.( ) vive com companheiro 2.( ) vive sem companheiro

- Escolaridade: 1.( ) Analfabeto 2.( ) Nível Fundamental 3.( ) Nível Médio 4.( ) Superior 5.( ) Pós - graduação

- Religião:1.( ) Católica $\quad$ 2.( ) Evangélica. Especifique:
3.( ) Espírita
4.( ) Candomblé
5.( ) Ateu

6.( ) Outra. Especifique

- Praticante da religião: 1.( ) Não. 2. ( ). Sim. Tipo de prática

- Há quanto tempo sabe que tem a doença?

- Tem outras doenças associadas? 1. ( ) Não 2. ( )Sim. Especifique:

- Fuma atualmente?

1.( ) Não. Ex- Fumante? 1.( ) Não 2.( ) Sim. Há quanto tempo parou?

Fumou durante quanto tempo? Quantos maços por dia?

2.( ) Sim. Fuma há quanto tempo? Quantos maços por dia?

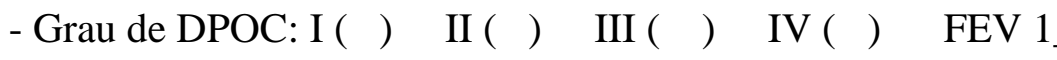

Relação FEV1/FVC:

Data 
ANEXOS 
ANEXO 01

\section{APROVAÇĀO}

A Comissão de Ética para Análise de Projetos de Pesquisa CAPPesa da Diretoria Clínica do Hospital das Clínicas e da Faculdade de Medicina da Universidade de São Paulo, em sessão de 04/06/2008, APROVOU o Protocolo de Pesquisa $n^{\circ}$ 0295/08, intitulado: "QUALIDADE DE VIDA E BEM ESTAR ESPIRITUAL EM PACIENTES COM DOENÇA PULMONAR OBSTRUTIVA CRONICA apresentado pelo Departamento de CÁRDIOPNEUMOLOGIA, inclusive o Termo de Consentimento Livre e Esclarecido, conforme parecer anexo.

Cabe ao pesquisador elaborar e apresentar à CAPPesq. os relatórios parciais e final sobre a pesquisa (Resolução do Conselho Nacional de Saúde $n^{\circ} 196$, de 10/10/1996, inciso IX.2, letra "c").

Pesquisador (a) Responsável: Prof. Dr. Rafael Stelmach

Sra. Miako Kimura

Pesquisador (a) Executante: Sra. Maira Shiramizu da Silva

CAPPesq, 05 de Junho de 2008

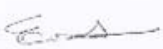

Prof. Dr. Eduardo Massad Presidente da Comissão de Ética para Análise de Projetos de Pesquisa

Comissăo de Ética para Análise de Projetos de Pesquisa do HCFMUSP e da FMUSP Diretoria Clinica do Hospital das Clinicas da Faculdade de Medicina da Universidade de Sáo Paulo Rua Ovidio Pires de Campos, 255, $5^{\circ}$ andar - CEP 05403010 - São Paulo - SP Fone: 01130696442 Fax. 01130696492 e-mail: cappesq@hcnet.usp.br $/$ secretariacappesq2@henet.us, br.br 
ANEXO 02

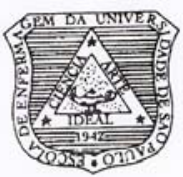

\author{
UNIVERSIDADE DE SAOO PAULO \\ ESCOLA DE ENFERMAGEM \\ Av. Dr. Enèas de Carvalho Aguiar, 419 - CEP 05403-000 \\ I Fone: 3061-7548 - Fax.: 3061-7548 \\ C.P. 41633 -CEP 05422-970 - e-mail.: edipesq@usp.br
}

São Paulo, 07 de abril de 2008.

Ilm. ${ }^{\text {a Sr. }}{ }^{\mathrm{a}}$

Prof. ${ }^{a} \mathrm{Dr}^{\mathrm{a}}$ Miako Kimura

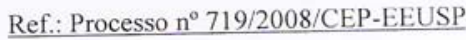

Prezada Senhora,

Em atenção à solicitação referente à análise do projeto "Espiritualidade e qualidade de vida de pacientes com doença pulmonar obstrutiva crônical", informamos que o mesmo foi considerado aprovado pelo Comitê de Ética em Pesquisa da Escola de Enfermagem da Universidade de São Paulo (CEP/EEUSP).

Analisado sob o aspecto ético-legal, atende às exigências da Resolução ${ }^{\circ}$ 196/96 do Conselho Nacional de Saúde.

Esclarecemos que após o término da pesquisa, os resultados obtidos deverão ser encaminhados ao CEP/EEUSP, para serem anexados ao processo.

Atenciosamente,

Prof. ${ }^{\text {a }}$ Dr. ${ }^{3}$ Maria de Fátima Prado Fernandes Coordenadora do Comitê de Ética em Pesquisa da Escola de Enfermagem da Universidade de São Paulo 
ANEXO 03

\section{Escala de Bem-Estar Espiritual}

(versão traduzida e adaptada por Volcan et al., 2003)

A seguir, serão apresentadas vinte sentenças. Para cada uma delas, circule a opção que indica a extensão de sua concordância ou discordância conforme sua experiência pessoal.

\begin{tabular}{|c|c|c|c|c|c|c|}
\hline $\begin{array}{l}\text { 01. Eu não encontro muita } \\
\text { satisfação em uma oração } \\
\text { privada com Deus. }\end{array}$ & $\begin{array}{l}\text { Concordo } \\
\text { Fortemente }\end{array}$ & $\begin{array}{l}\text { Concordo } \\
\text { Moderadamente }\end{array}$ & Concordo & Discordo & $\begin{array}{c}\text { Discordo } \\
\text { Moderadamente }\end{array}$ & $\begin{array}{l}\text { Discordo } \\
\text { Fortemente }\end{array}$ \\
\hline $\begin{array}{l}\text { 02. Eu não sei quem sou, de } \\
\text { onde venho ou para onde vou. }\end{array}$ & $\begin{array}{c}\text { Concordo } \\
\text { Fortemente }\end{array}$ & $\begin{array}{c}\text { Concordo } \\
\text { Moderadamente }\end{array}$ & Concordo & Discordo & $\begin{array}{c}\text { Discordo } \\
\text { Moderadamente } \\
\end{array}$ & $\begin{array}{l}\text { Discordo } \\
\text { Fortemente }\end{array}$ \\
\hline $\begin{array}{l}\text { 03. Eu acredito que Deus me } \\
\text { ama e se importa comigo. }\end{array}$ & $\begin{array}{l}\text { Concordo } \\
\text { Fortemente }\end{array}$ & $\begin{array}{c}\text { Concordo } \\
\text { Moderadamente }\end{array}$ & Concordo & Discordo & $\begin{array}{c}\text { Discordo } \\
\text { Moderadamente }\end{array}$ & $\begin{array}{l}\text { Discordo } \\
\text { Fortemente }\end{array}$ \\
\hline $\begin{array}{l}\text { 04. Eu sinto que a vida é uma } \\
\text { experiência positiva. }\end{array}$ & $\begin{array}{l}\text { Concordo } \\
\text { Fortemente }\end{array}$ & $\begin{array}{c}\text { Concordo } \\
\text { Moderadamente }\end{array}$ & Concordo & Discordo & $\begin{array}{c}\text { Discordo } \\
\text { Moderadamente }\end{array}$ & $\begin{array}{l}\text { Discordo } \\
\text { Fortemente }\end{array}$ \\
\hline $\begin{array}{l}\text { 05. Eu acredito que Deus é } \\
\text { impessoal e não está interessado } \\
\text { nas minhas situações diárias. }\end{array}$ & $\begin{array}{c}\text { Concordo } \\
\text { Fortemente }\end{array}$ & $\begin{array}{c}\text { Concordo } \\
\text { Moderadamente }\end{array}$ & Concordo & Discordo & $\begin{array}{c}\text { Discordo } \\
\text { Moderadamente }\end{array}$ & $\begin{array}{l}\text { Discordo } \\
\text { Fortemente }\end{array}$ \\
\hline $\begin{array}{l}\text { 06. Eu me sinto intranquilo sobre } \\
\text { o meu futuro. }\end{array}$ & $\begin{array}{l}\text { Concordo } \\
\text { Fortemente }\end{array}$ & $\begin{array}{c}\text { Concordo } \\
\text { Moderadamente }\end{array}$ & Concordo & Discordo & $\begin{array}{c}\text { Discordo } \\
\text { Moderadamente }\end{array}$ & $\begin{array}{l}\text { Discordo } \\
\text { Fortemente }\end{array}$ \\
\hline $\begin{array}{l}\text { 07. Eu tenho uma relação } \\
\text { pessoal significativa com Deus. }\end{array}$ & $\begin{array}{l}\text { Concordo } \\
\text { Fortemente }\end{array}$ & $\begin{array}{c}\text { Concordo } \\
\text { Moderadamente }\end{array}$ & Concordo & Discordo & $\begin{array}{c}\text { Discordo } \\
\text { Moderadamente }\end{array}$ & $\begin{array}{l}\text { Discordo } \\
\text { Fortemente }\end{array}$ \\
\hline $\begin{array}{l}\text { 08. Eu me sinto realizado e } \\
\text { satisfeito com a vida. }\end{array}$ & $\begin{array}{l}\text { Concordo } \\
\text { Fortemente }\end{array}$ & $\begin{array}{c}\text { Concordo } \\
\text { Moderadamente }\end{array}$ & Concordo & Discordo & $\begin{array}{c}\text { Discordo } \\
\text { Moderadamente }\end{array}$ & $\begin{array}{l}\text { Discordo } \\
\text { Fortemente }\end{array}$ \\
\hline $\begin{array}{l}\text { 09. Eu não recebo muita força } \\
\text { pessoal e apoio do meu Deus. }\end{array}$ & $\begin{array}{c}\text { Concordo } \\
\text { Fortemente } \\
\end{array}$ & $\begin{array}{c}\text { Concordo } \\
\text { Moderadamente }\end{array}$ & Concordo & Discordo & $\begin{array}{c}\text { Discordo } \\
\text { Moderadamente }\end{array}$ & $\begin{array}{l}\text { Discordo } \\
\text { Fortemente }\end{array}$ \\
\hline $\begin{array}{l}\text { 10. Eu tenho um sentimento de } \\
\text { bem-estar em relação à direção } \\
\text { em que a minha vida está } \\
\text { encaminhada. }\end{array}$ & $\begin{array}{l}\text { Concordo } \\
\text { Fortemente }\end{array}$ & $\begin{array}{c}\text { Concordo } \\
\text { Moderadamente }\end{array}$ & Concordo & Discordo & $\begin{array}{c}\text { Discordo } \\
\text { Moderadamente }\end{array}$ & $\begin{array}{l}\text { Discordo } \\
\text { Fortemente }\end{array}$ \\
\hline $\begin{array}{l}\text { 11. Eu acredito que Deus está } \\
\text { preocupado com meus } \\
\text { problemas. }\end{array}$ & $\begin{array}{l}\text { Concordo } \\
\text { Fortemente }\end{array}$ & $\begin{array}{c}\text { Concordo } \\
\text { Moderadamente }\end{array}$ & Concordo & Discordo & $\begin{array}{c}\text { Discordo } \\
\text { Moderadamente }\end{array}$ & $\begin{array}{l}\text { Discordo } \\
\text { Fortemente }\end{array}$ \\
\hline $\begin{array}{l}\text { 12. Eu não tenho muita } \\
\text { satisfação em minha vida. }\end{array}$ & $\begin{array}{l}\text { Concordo } \\
\text { Fortemente }\end{array}$ & $\begin{array}{c}\text { Concordo } \\
\text { Moderadamente }\end{array}$ & Concordo & Discordo & $\begin{array}{c}\text { Discordo } \\
\text { Moderadamente }\end{array}$ & $\begin{array}{l}\text { Discordo } \\
\text { Fortemente }\end{array}$ \\
\hline $\begin{array}{l}\text { 13. Eu não tenho uma relação } \\
\text { pessoal satisfatória com Deus. }\end{array}$ & $\begin{array}{l}\text { Concordo } \\
\text { Fortemente }\end{array}$ & $\begin{array}{c}\text { Concordo } \\
\text { Moderadamente }\end{array}$ & Concordo & Discordo & $\begin{array}{c}\text { Discordo } \\
\text { Moderadamente }\end{array}$ & $\begin{array}{l}\text { Discordo } \\
\text { Fortemente }\end{array}$ \\
\hline $\begin{array}{l}\text { 14. Eu me sinto bem em relação } \\
\text { ao meu futuro. }\end{array}$ & $\begin{array}{l}\text { Concordo } \\
\text { Fortemente }\end{array}$ & $\begin{array}{c}\text { Concordo } \\
\text { Moderadamente }\end{array}$ & Concordo & Discordo & $\begin{array}{c}\text { Discordo } \\
\text { Moderadamente }\end{array}$ & $\begin{array}{l}\text { Discordo } \\
\text { Fortemente }\end{array}$ \\
\hline $\begin{array}{l}\text { 15. Meu relacionamento com } \\
\text { Deus me ajuda a não me sentir } \\
\text { sozinho. }\end{array}$ & $\begin{array}{c}\text { Concordo } \\
\text { Fortemente }\end{array}$ & $\begin{array}{c}\text { Concordo } \\
\text { Moderadamente }\end{array}$ & Concordo & Discordo & $\begin{array}{c}\text { Discordo } \\
\text { Moderadamente }\end{array}$ & $\begin{array}{l}\text { Discordo } \\
\text { Fortemente }\end{array}$ \\
\hline $\begin{array}{l}\text { 16. Eu sinto que a vida é cheia } \\
\text { de conflitos e infelicidade. }\end{array}$ & $\begin{array}{c}\text { Concordo } \\
\text { Fortemente }\end{array}$ & $\begin{array}{c}\text { Concordo } \\
\text { Moderadamente }\end{array}$ & Concordo & Discordo & $\begin{array}{c}\text { Discordo } \\
\text { Moderadamente }\end{array}$ & $\begin{array}{l}\text { Discordo } \\
\text { Fortemente }\end{array}$ \\
\hline $\begin{array}{l}\text { 17. Eu me sinto mais realizado } \\
\text { quando estou em plena } \\
\text { comunhão com Deus. }\end{array}$ & $\begin{array}{l}\text { Concordo } \\
\text { Fortemente }\end{array}$ & $\begin{array}{c}\text { Concordo } \\
\text { Moderadamente }\end{array}$ & Concordo & Discordo & $\begin{array}{c}\text { Discordo } \\
\text { Moderadamente }\end{array}$ & $\begin{array}{l}\text { Discordo } \\
\text { Fortemente }\end{array}$ \\
\hline $\begin{array}{l}\text { 18. A vida não tem muito } \\
\text { significado. }\end{array}$ & $\begin{array}{l}\text { Concordo } \\
\text { Fortemente }\end{array}$ & $\begin{array}{c}\text { Concordo } \\
\text { Moderadamente }\end{array}$ & Concordo & Discordo & $\begin{array}{c}\text { Discordo } \\
\text { Moderadamente }\end{array}$ & $\begin{array}{l}\text { Discordo } \\
\text { Fortemente }\end{array}$ \\
\hline $\begin{array}{l}\text { 19. A minha relação com Deus } \\
\text { contribui para a minha sensação } \\
\text { de bem-estar. }\end{array}$ & $\begin{array}{l}\text { Concordo } \\
\text { Fortemente }\end{array}$ & $\begin{array}{c}\text { Concordo } \\
\text { Moderadamente }\end{array}$ & Concordo & Discordo & $\begin{array}{c}\text { Discordo } \\
\text { Moderadamente }\end{array}$ & $\begin{array}{l}\text { Discordo } \\
\text { Fortemente }\end{array}$ \\
\hline $\begin{array}{l}\text { 20. Eu acredito que há um } \\
\text { sentido real para a minha vida. }\end{array}$ & $\begin{array}{l}\text { Concordo } \\
\text { Fortemente }\end{array}$ & $\begin{array}{c}\text { Concordo } \\
\text { Moderadamente }\end{array}$ & Concordo & Discordo & $\begin{array}{c}\text { Discordo } \\
\text { Moderadamente }\end{array}$ & $\begin{array}{l}\text { Discordo } \\
\text { Fortemente }\end{array}$ \\
\hline
\end{tabular}


ANEXO 04

Pontuação dos Itens da Escala de Bem Estar Espiritual

\begin{tabular}{|c|c|c|c|c|c|c|c|}
\hline Item & Sub-Escala & & & & & & \\
\hline $\begin{array}{l}\text { 1. Eu não encontro muita satisfação } \\
\text { em uma oração privada com Deus. }\end{array}$ & RELIGIOSO & $\begin{array}{c}\mathrm{CF} \\
1\end{array}$ & $\begin{array}{c}\text { CM } \\
2\end{array}$ & $\begin{array}{l}C \\
3\end{array}$ & $\begin{array}{l}D \\
4\end{array}$ & $\begin{array}{c}\text { DM } \\
5\end{array}$ & $\begin{array}{c}\text { DF } \\
6\end{array}$ \\
\hline $\begin{array}{l}\text { 2. Eu não sei quem sou, de onde } \\
\text { venho ou para onde vou. }\end{array}$ & EXISTENCIAL & $\begin{array}{c}\mathrm{CF} \\
1\end{array}$ & $\begin{array}{c}\text { CM } \\
2\end{array}$ & $\begin{array}{l}\text { C } \\
3\end{array}$ & $\begin{array}{l}D \\
4\end{array}$ & $\begin{array}{c}\text { DM } \\
5\end{array}$ & $\begin{array}{c}\text { DF } \\
6\end{array}$ \\
\hline $\begin{array}{l}\text { 3. Eu acredito que Deus me ama e } \\
\text { se importa comigo. }\end{array}$ & RELIGIOSO & $\begin{array}{c}\text { CF } \\
6\end{array}$ & $\begin{array}{c}\mathrm{CM} \\
5\end{array}$ & $\begin{array}{l}C \\
4\end{array}$ & $\begin{array}{l}\text { D } \\
3\end{array}$ & $\begin{array}{c}\text { DM } \\
2\end{array}$ & $\begin{array}{c}\text { DF } \\
1\end{array}$ \\
\hline $\begin{array}{l}\text { 4. Eu sinto que a vida é uma } \\
\text { experiência positiva. }\end{array}$ & EXISTENCIAL & $\begin{array}{c}\text { CF } \\
6\end{array}$ & $\begin{array}{c}\text { CM } \\
5\end{array}$ & $\begin{array}{l}\mathrm{C} \\
4\end{array}$ & $\begin{array}{l}\mathrm{D} \\
3\end{array}$ & $\begin{array}{c}\text { DM } \\
2 \\
\end{array}$ & $\begin{array}{c}\text { DF } \\
1 \\
\end{array}$ \\
\hline $\begin{array}{l}\text { 5. Eu acredito que Deus é impessoal } \\
\text { e não está interessado nas minhas } \\
\text { situações diárias. }\end{array}$ & RELIGIOSO & $\begin{array}{c}\mathrm{CF} \\
1\end{array}$ & $\begin{array}{c}\text { CM } \\
2\end{array}$ & $\begin{array}{l}\mathrm{C} \\
3\end{array}$ & $\begin{array}{l}\mathrm{D} \\
4\end{array}$ & $\begin{array}{c}\mathrm{DM} \\
5\end{array}$ & $\begin{array}{c}\text { DF } \\
6\end{array}$ \\
\hline $\begin{array}{l}\text { 6. Eu me sinto intranquilo sobre o } \\
\text { meu futuro. }\end{array}$ & EXISTENCIAL & $\begin{array}{c}\mathrm{CF} \\
1 \\
\end{array}$ & $\begin{array}{c}\mathrm{CM} \\
2\end{array}$ & $\begin{array}{l}\mathrm{C} \\
3\end{array}$ & $\begin{array}{l}\mathrm{D} \\
4 \\
\end{array}$ & $\begin{array}{c}\mathrm{DM} \\
5\end{array}$ & $\begin{array}{c}\text { DF } \\
6 \\
\end{array}$ \\
\hline $\begin{array}{l}\text { 7. Eu tenho uma relação pessoal } \\
\text { significativa com Deus. }\end{array}$ & RELIGIOSO & $\begin{array}{c}\text { CF } \\
6\end{array}$ & $\begin{array}{c}\text { CM } \\
5\end{array}$ & $\begin{array}{l}\mathrm{C} \\
4\end{array}$ & $\begin{array}{l}\text { D } \\
3\end{array}$ & $\begin{array}{c}\text { DM } \\
2\end{array}$ & $\begin{array}{c}\text { DF } \\
1\end{array}$ \\
\hline $\begin{array}{l}\text { 8. Eu me sinto realizado e } \\
\text { satisfeito com a vida. }\end{array}$ & EXISTENCIAL & $\begin{array}{c}\text { CF } \\
6\end{array}$ & $\begin{array}{c}\mathrm{CM} \\
5\end{array}$ & $\begin{array}{l}C \\
4\end{array}$ & $\begin{array}{l}\text { D } \\
3\end{array}$ & $\begin{array}{c}\text { DM } \\
2\end{array}$ & $\begin{array}{c}\text { DF } \\
1\end{array}$ \\
\hline $\begin{array}{l}\text { 9. Eu não recebo muita força pessoal } \\
\text { e apoio do meu Deus. }\end{array}$ & RELIGIOSO & $\begin{array}{c}\mathrm{CF} \\
1 \\
\end{array}$ & $\begin{array}{c}\text { CM } \\
2\end{array}$ & $\begin{array}{l}\mathrm{C} \\
3\end{array}$ & $\begin{array}{l}\mathrm{D} \\
4 \\
\end{array}$ & $\begin{array}{c}\text { DM } \\
5\end{array}$ & $\begin{array}{c}\text { DF } \\
6 \\
\end{array}$ \\
\hline $\begin{array}{l}\text { 10. Eu tenho um sentimento de } \\
\text { bem-estar em relação à direção em } \\
\text { que a minha vida está } \\
\text { encaminhada. }\end{array}$ & EXISTENCIAL & $\begin{array}{c}\text { CF } \\
6\end{array}$ & $\begin{array}{c}\text { CM } \\
5\end{array}$ & $\begin{array}{l}\mathrm{C} \\
4\end{array}$ & $\begin{array}{l}\text { D } \\
3\end{array}$ & $\begin{array}{c}\text { DM } \\
2\end{array}$ & $\begin{array}{c}\text { DF } \\
1\end{array}$ \\
\hline $\begin{array}{l}\text { 11. Eu acredito que Deus está } \\
\text { preocupado com meus problemas. }\end{array}$ & RELIGIOSO & $\begin{array}{c}\text { CF } \\
6\end{array}$ & $\begin{array}{c}\mathrm{CM} \\
5\end{array}$ & $\begin{array}{l}\mathrm{C} \\
4\end{array}$ & $\begin{array}{l}\text { D } \\
3\end{array}$ & $\begin{array}{c}\text { DM } \\
2\end{array}$ & $\begin{array}{c}\text { DF } \\
1\end{array}$ \\
\hline $\begin{array}{l}\text { 12. Eu não tenho muita satisfação } \\
\text { em minha vida. }\end{array}$ & EXISTENCIAL & $\begin{array}{c}\mathrm{CF} \\
1\end{array}$ & $\begin{array}{c}\text { CM } \\
2\end{array}$ & $\begin{array}{l}\mathrm{C} \\
3\end{array}$ & $\begin{array}{l}\mathrm{D} \\
4\end{array}$ & $\begin{array}{c}\mathrm{DM} \\
5\end{array}$ & $\begin{array}{c}\text { DF } \\
6\end{array}$ \\
\hline $\begin{array}{l}\text { 13. Eu não tenho uma relação } \\
\text { pessoal satisfatória com Deus. }\end{array}$ & RELIGIOSO & $\begin{array}{c}\mathrm{CF} \\
1 \\
\end{array}$ & $\begin{array}{c}\mathrm{CM} \\
2 \\
\end{array}$ & $\begin{array}{l}\mathrm{C} \\
3 \\
\end{array}$ & $\begin{array}{l}\mathrm{D} \\
4\end{array}$ & $\begin{array}{c}\text { DM } \\
5\end{array}$ & $\begin{array}{c}\text { DF } \\
6\end{array}$ \\
\hline $\begin{array}{l}\text { 14. Eu me sinto bem em relação } \\
\text { ao meu futuro. }\end{array}$ & EXISTENCIAL & $\begin{array}{c}\text { CF } \\
6\end{array}$ & $\begin{array}{c}\mathrm{CM} \\
5\end{array}$ & $\begin{array}{l}C \\
4\end{array}$ & $\begin{array}{l}\text { D } \\
3\end{array}$ & $\begin{array}{l}\text { DM } \\
2\end{array}$ & $\begin{array}{c}\text { DF } \\
1\end{array}$ \\
\hline $\begin{array}{l}\text { 15. Meu relacionamento com Deus } \\
\text { me ajuda a não me sentir sozinho. }\end{array}$ & RELIGIOSO & $\begin{array}{c}\text { CF } \\
6\end{array}$ & $\begin{array}{c}\mathrm{CM} \\
5\end{array}$ & $\begin{array}{l}\mathrm{C} \\
4\end{array}$ & $\begin{array}{l}\text { D } \\
3\end{array}$ & $\begin{array}{c}\text { DM } \\
2\end{array}$ & $\begin{array}{c}\text { DF } \\
1\end{array}$ \\
\hline $\begin{array}{l}\text { 16. Eu sinto que a vida é cheia de } \\
\text { conflitos e infelicidade. }\end{array}$ & EXISTENCIAL & $\begin{array}{c}\mathrm{CF} \\
1\end{array}$ & $\begin{array}{c}\mathrm{CM} \\
2\end{array}$ & $\begin{array}{l}\mathrm{C} \\
3\end{array}$ & $\begin{array}{l}\mathrm{D} \\
4\end{array}$ & $\begin{array}{c}\text { DM } \\
5\end{array}$ & $\begin{array}{c}\text { DF } \\
6\end{array}$ \\
\hline $\begin{array}{l}\text { 17. Eu me sinto mais realizado } \\
\text { quando estou em plena comunhão } \\
\text { com Deus. }\end{array}$ & RELIGIOSO & $\begin{array}{c}\text { CF } \\
6\end{array}$ & $\begin{array}{c}\text { CM } \\
5\end{array}$ & $\begin{array}{l}\mathrm{C} \\
4\end{array}$ & $\begin{array}{l}\text { D } \\
3\end{array}$ & $\begin{array}{l}\text { DM } \\
2\end{array}$ & $\begin{array}{c}\mathrm{DF} \\
1\end{array}$ \\
\hline 18. A vida não tem muito significado. & EXISTENCIAL & $\begin{array}{c}\mathrm{CF} \\
1 \\
\end{array}$ & $\begin{array}{c}\text { CM } \\
2\end{array}$ & $\begin{array}{l}\mathrm{C} \\
3 \\
\end{array}$ & $\begin{array}{l}\mathrm{D} \\
4 \\
\end{array}$ & $\begin{array}{c}\mathrm{DM} \\
5\end{array}$ & $\begin{array}{c}\text { DF } \\
6\end{array}$ \\
\hline $\begin{array}{l}\text { 19. A minha relação com Deus } \\
\text { contribui para a minha sensação } \\
\text { de bem-estar. }\end{array}$ & RELIGIOSO & $\begin{array}{c}\text { CF } \\
6\end{array}$ & $\begin{array}{c}\text { CM } \\
5\end{array}$ & $\begin{array}{l}\text { C } \\
4\end{array}$ & $\begin{array}{l}\text { D } \\
3\end{array}$ & $\begin{array}{c}\text { DM } \\
2\end{array}$ & $\begin{array}{c}\text { DF } \\
1\end{array}$ \\
\hline $\begin{array}{l}\text { 20. Eu acredito que há um sentido } \\
\text { real para a minha vida. }\end{array}$ & EXISTENCIAL & $\begin{array}{c}\text { CF } \\
6\end{array}$ & $\begin{array}{c}\mathrm{CM} \\
5\end{array}$ & $\begin{array}{l}\mathrm{C} \\
4\end{array}$ & $\begin{array}{l}\text { D } \\
3\end{array}$ & $\begin{array}{c}\text { DM } \\
2\end{array}$ & $\begin{array}{c}\text { DF } \\
1\end{array}$ \\
\hline
\end{tabular}


ANEXO 05

\section{QUESTIONÁRIO DO HOSPITAL SAINT GEORGE NA DOENÇA RESPIRATÓRIA}

(versão adaptada e validada por Sousa, Jardim e Jones, 2000)

Este questionário nos ajuda a compreender até que ponto a sua dificuldade respiratória o perturba e afeta a sua vida. Nós o utilizamos para descobrir quais os aspectos da sua doença que causam mais problemas. Estamos interessados em saber o que você sente e não o que os médicos, enfermeiras e fisioterapeutas acham que você sente. Leia atentamente as instruções. Esclareça as dúvidas que tiver. Não perca muito tempo nas suas respostas.

\section{Parte 1}

Nas perguntas abaixo, assinale aquela que melhor identifica seus problemas respiratórios no último ano. Assinale um só quadrado para as questões de 01 a 08 :

\begin{tabular}{|l|l|l|l|l|l|}
\hline & $\begin{array}{c}\text { Maioria dos } \\
\text { dias da } \\
\text { semana (5-7 } \\
\text { dias) }\end{array}$ & $\begin{array}{c}\text { Vários dias } \\
\text { na semana } \\
\text { (2-4 dias) }\end{array}$ & $\begin{array}{c}\text { Alguns dias } \\
\text { no mês }\end{array}$ & $\begin{array}{c}\text { Só com infecções } \\
\text { respiratórias }\end{array}$ & nunca \\
\hline $\begin{array}{l}\text { 1) durante o } \\
\text { último ano } \\
\text { tossi }\end{array}$ & & & & & \\
\hline $\begin{array}{l}\text { 2) durante o } \\
\text { último ano tive } \\
\text { catarro }\end{array}$ & & & & & \\
\hline $\begin{array}{l}\text { 3) durante o } \\
\text { último ano tive } \\
\text { falta de ar derante o }\end{array}$ & & & & & \\
\hline $\begin{array}{l}\text { 4) durante } \\
\text { último ano tive } \\
\text { "chiado no }\end{array}$ & & & & & \\
peito" & & & & \\
\hline
\end{tabular}

5) Durante o último ano, quantas crises graves de problemas respiratórios você teve?

\begin{tabular}{|c|c|c|c|c|}
\hline Mais de 3 & 3 & 2 & 1 & nenhuma \\
\hline
\end{tabular}


6) Quanto tempo durou a pior destas crises? (passe para a pergunta 7 se não teve crises graves)

\begin{tabular}{|c|c|c|c|}
\hline 1 semana ou mais & 3 ou mais dias & 1 ou 2 dias & Menos de 1 dia \\
\hline & & & \\
\hline
\end{tabular}

7) Durante o último ano, em uma semana considerada como habitual, quantos dias bons (com poucos problemas respiratórios) você teve:

\begin{tabular}{|c|c|c|c|c|}
\hline Nenhum dia & 1 ou 2 dias & ou 4 dias & $\begin{array}{c}\text { Quase todos } \\
\text { os dias }\end{array}$ & Todos os dias \\
\hline & & & & \\
\hline
\end{tabular}

8) No caso de ter tido "chiado no peito", ele é pior de manhã? Sim ( ) Não ( )

\section{Parte 2}

\section{Seção 1}

A) Assinale um só quadrado para descrever a sua doença respiratória:

\begin{tabular}{|l|l|l|l|l|}
$\begin{array}{l}\hat{E} \text { o meu maior } \\
\text { problema }\end{array}$ & $\begin{array}{l}\text { Causa-me muitos } \\
\text { problemas }\end{array}$ & $\begin{array}{l}\text { Causa-me alguns } \\
\text { problemas }\end{array}$ & $\begin{array}{l}\text { Não me causa } \\
\text { nenhum problema }\end{array}$ \\
\hline
\end{tabular}

B) Se você já teve um trabalho pago, assinale um dos quadrados:

(passe para a Seção 2, se você não trabalha)

- Minha doença respiratória obrigou-me a parar de trabalhar

- Minha doença respiratória interfere com o meu trabalho normal ou já me obrigou a mudar de trabalho $\square$

- Minha doença respiratória não afeta o meu trabalho

\section{Seção 2}

As respostas abaixo se referem às atividades que podem provocar falta de ar. Assinale com um " $x$ " no quadrado de cada questão abaixo, indicando a resposta Sim ou Não, de acordo com o seu caso atualmente.

\begin{tabular}{|l|l|l|}
\hline & Sim & Não \\
\hline Sentado ou deitado & & \\
\hline Tomando banho ou vestindo & & \\
\hline Caminhando dentro de casa & & \\
\hline Caminhando em terreno plano & & \\
\hline Subindo um lance de escada & & \\
\hline Subindo ladeiras & & \\
\hline Praticando esportes ou jogos que impliquem esforço físico & & \\
\hline
\end{tabular}




\section{Seção 3}

Mais algumas perguntas sobre a sua tosse e a sua falta de ar nos últimos dias. Assinale com um " $x$ " no quadrado de cada pergunta abaixo, indicando a resposta Sim ou Não, de acordo com o seu caso:

\begin{tabular}{|l|l|l|}
\hline & Sim & Não \\
\hline Minha tosse causa-me dor & & \\
\hline Minha tosse deixa-se cansado & & \\
\hline Falta-me o ar quando falo & & \\
\hline Falta-me o ar quando dobro o corpo para frente & & \\
\hline Minha tosse ou falta de ar perturba o meu sono & & \\
\hline Fico exausto com facilidade & & \\
\hline
\end{tabular}

\section{Seção4}

Perguntas sobre outros efeitos causados pela sua doença respiratória nos últimos dias. Assinale com um " $x$ " no quadrado de cada pergunta abaixo, indicando a resposta Sim ou Não, de acordo com o seu caso:

\begin{tabular}{|l|l|l|}
\hline & Sim & Não \\
\hline Minha tosse ou falta de ar deixaram-me envergonhado em público & & \\
\hline $\begin{array}{l}\text { Minha doença respiratória é inconveniente para a minha família, } \\
\text { amigos ou vizinhos }\end{array}$ & & \\
\hline Tenho medo, ou mesmo pânico quando não consigo respirar & & \\
\hline Sinto que a minha doença respiratória escapa ao meu controle & & \\
\hline Eu espero nenhuma melhora da minha doença respiratória & & \\
\hline $\begin{array}{l}\text { Minha doença debilitou-me física e mentalmente, o que faz com que } \\
\text { eu precise da ajuda de alguém }\end{array}$ & & \\
\hline Parece-me perigoso fazer exercício & & \\
\hline Tudo o que eu faço, parece ser demais para a minha capacidade & & \\
\hline
\end{tabular}

\section{Seção 5}

Perguntas sobre a sua medicação. Assinale com um " $x$ " no quadrado de cada pergunta abaixo, indicando a resposta Sim ou Não, de acordo com o seu caso: (passe para a Seção 6 se não toma medicamentos)

\begin{tabular}{|l|l|l|}
\hline Minha medicação não está me ajudando muito & Sim & Não \\
\hline Fico envergonhado ao tomar medicamentos em público & & \\
\hline Minha medicação provoca-me efeitos colaterais desagradáveis & & \\
\hline Minha medicação interfere muito com o meu dia-a-dia & & \\
\hline
\end{tabular}




\section{Seção 6}

As perguntas seguintes se referem às atividades que podem ser afetadas pela sua doença respiratória. Assinale com um " $x$ " no quadrado de cada pergunta abaixo, indicando a resposta $\mathrm{Sim}$ se pelo menos uma parte da frase corresponde ao seu caso; se não, assinale Não.

\begin{tabular}{|l|l|l|}
\hline Leva muito tempo para lavar-me ou vestir-me & Sim & Não \\
\hline $\begin{array}{l}\text { Demoro muito tempo ou não consigo tomar banho de chuveiro ou na } \\
\text { banheira }\end{array}$ & & \\
\hline $\begin{array}{l}\text { Ando mais devagar que as outras pessoas, ou tenho que parar para } \\
\text { descansar }\end{array}$ & \\
\hline $\begin{array}{l}\text { Demoro muito tempo para realizar tarefas como o trabalho de casa, } \\
\text { ou tenho que parar para descansar }\end{array}$ & \\
\hline $\begin{array}{l}\text { Quando subo um lance de escada, vou muito devagar, ou tenho que } \\
\text { parar para descansar }\end{array}$ & \\
\hline $\begin{array}{l}\text { Se estou apressado ou caminho mais depressa, tenho que parar } \\
\text { para descansar ou ir mais devagar }\end{array}$ & \\
\hline $\begin{array}{l}\text { Por causa da minha respiração, tenho dificuldade para desenvolver } \\
\text { atividades como: subir ladeiras, carregar objetos subindo escadas, } \\
\text { dançar, praticar esporte leve }\end{array}$ & \\
\hline $\begin{array}{l}\text { Por causa da minha respiração, tenho dificuldades para desenvolver } \\
\text { atividades como: carregar grandes pesos, fazer "cooper" ou nadar }\end{array}$ & \\
\hline $\begin{array}{l}\text { Por causa da minha respiração, tenho dificuldade para desenvolver } \\
\text { atividades como: trabalho manual pesado, correr, andar de bicicleta, } \\
\text { nadar rápido, ou praticar esportes de competição. }\end{array}$ & \\
\hline
\end{tabular}

\section{Seção 7}

A) Assinale com um " $x$ " no quadrado de cada pergunta abaixo, indicando a resposta Sim ou Não, para indicar outras atividades que geralmente podem ser afetadas pela sua doença respiratória no seu dia-a-dia: (não se esqueça que Sim só se aplica ao seu caso quando você não puder fazer essa atividade devido à sua doença respiratória).

\begin{tabular}{|l|l|l|}
\hline & Sim & Não \\
\hline Praticar esportes ou jogos que impliquem esforço físico & & \\
\hline Sair de casa para me divertir & & \\
\hline Sair de casa para fazer compras & & \\
\hline Fazer o trabalho de casa & & \\
\hline Sair da cama ou da cadeira & & \\
\hline
\end{tabular}


B) A lista seguinte descreve uma série de outras atividades que o seu problema respiratório pode impedir você de realizar (você não tem que assinalar nenhuma das atividades, pretendemos apenas lembrá-lo das atividades que podem ser afetadas pela sua falta de ar).

\begin{tabular}{|l|l|}
\hline Dar passeios a pé ou passear com o seu cão & \\
\hline Fazer o trabalho doméstico ou jardinagem & \\
\hline Ter relações sexuais & \\
\hline Ir à igreja, bar ou locais de diversão & \\
\hline Sair com mau tempo ou permanecer e locais com fumaça de cigarro & \\
\hline Visitar a família e os amigos ou brincar com as crianças & \\
\hline
\end{tabular}

Por favor, escreva qualquer outra atividade importante que o seu problema pode impedi-lo de fazer:

C) Das questões abaixo relacionadas, assinale somente aquela que melhor define a forma como você é afetado pela sua doença respiratória:

Não me impede de fazer nenhuma das coisas que eu gostaria de fazer Impede-me de fazer uma ou duas coisas que eu gostaria de fazer Impede-me de fazer a maioria das coisas que eu gostaria de fazer Impede-me de fazer tudo o que eu gostaria de fazer

Obrigado por responder ao questionário. Antes de terminar verifique se você respondeu todas as perguntas. 
ANEXO 06

\section{ALGORITMO PARA PONTUAÇÃO DO SAINT GEORGE RESPIRATORY QUESTIONNAIRE}

PARTE 1

\begin{tabular}{|l|c|c|c|c|c|}
\hline & $\begin{array}{l}\text { Maioria dos } \\
\text { dias da } \\
\text { semana (5-7 } \\
\text { dias) }\end{array}$ & $\begin{array}{l}\text { Vários } \\
\text { dias na } \\
\text { semana } \\
\text { (2-4 dias) }\end{array}$ & $\begin{array}{l}\text { Alguns } \\
\text { dias no } \\
\text { mês }\end{array}$ & $\begin{array}{l}\text { Só com } \\
\text { infecções } \\
\text { respiratórias }\end{array}$ & Nunca \\
\hline $\begin{array}{l}\text { 1) durante o } \\
\text { último ano } \\
\text { tossi }\end{array}$ & 80,6 & 63,2 & 29,3 & 28,1 & 0 \\
\hline $\begin{array}{l}\text { 2) durante o } \\
\text { último ano tive } \\
\text { catarro }\end{array}$ & 76,8 & 60,0 & 34,0 & 30,2 & 0 \\
\hline $\begin{array}{l}\text { 3) durante o } \\
\text { último ano tive } \\
\text { falta de ar }\end{array}$ & 87,2 & 71,4 & 43,7 & 35,7 & 0 \\
\hline $\begin{array}{l}\text { 4) durante o } \\
\text { último ano tive } \\
\text { "chiado no } \\
\text { peito" }\end{array}$ & 86,2 & 71,0 & 45,6 & 36,4 & 0 \\
\hline
\end{tabular}

5) Durante o último ano, quantas crises graves de problemas respiratórios você teve?

mais de 3

3 crises

2 crises

1 crise

nenhuma crise

6) Quanto tempo durou a pior das crises?

1 Semana ou mais

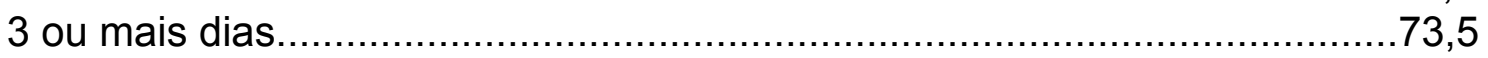

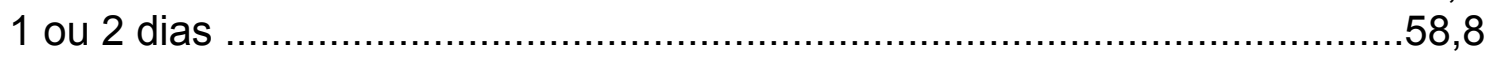

Menos de $1 \mathrm{dia}$................................................................................. 41,9

7) Durante o último ano, em uma semana considerada como habitual, quantos dias bons (com poucos problemas respiratórios) teve:

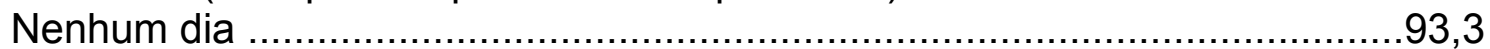

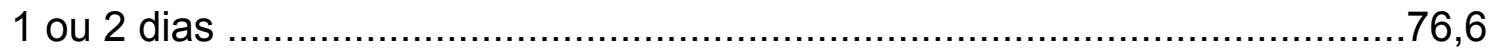

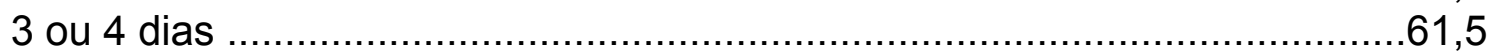

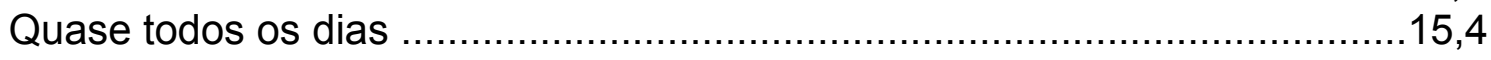

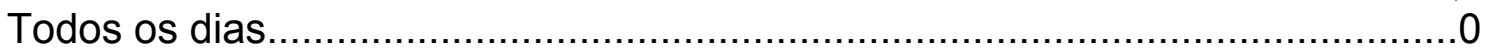

8) No caso de ter tido "chiado no peito", era pior de manhã?

Sim 62,0

Não. 0 


\section{PARTE 2}

\section{SEÇÃO 1}

Como descreve a doença respiratória:

É o meu maior problema

Causa-me muitos problemas

Causa-me alguns problemas

Não me causa nenhum problema.

Em relação ao seu trabalho:

Minha doença respiratória obrigou-me a parar de trabalhar

Minha doença respiratória interfere com o meu trabalho normal ou já me obrigou a mudar de trabalho

Minha doença respiratória não afeta o meu trabalho.

\section{SEÇÃO 2}

As respostas abaixo referem-se às atividades que podem provocar falta de ar, indicando a resposta sim ou não, de acordo com o caso atual:

sentado ou deitado 90,6

tomando banho ou vestindo

caminhando dentro de casa 80,2

caminhando em terreno plano

subindo um lance de escadas.

subindo ladeiras

praticando esportes ou jogos que impliquem esforço físico.

\section{SEÇÃO 3}

As questões abaixo são referentes à tosse e falta de ar

minha tosse causa-me dor.

minha tosse deixa-me cansado ........................................................ 79,1

falta-me o ar quando falo ..................................................................... 84,5

falta-me o ar quando dobro o corpo para a frente ………........................... 76,8

minha tosse ou falta de ar perturba meu sono ..................................................

fico exausto com facilidade.......................................................................

\section{SEÇÃO 4}

Indica a resposta sim ou não, para definir o estado que a doença respiratória tem sobre a pessoa.

minha tosse ou falta de ar, deixam-me envergonhado em público.

minha doença respiratória é inconveniente para a minha família, amigos e

vizinhos.

tenho medo ou mesmo pânico quando não consigo respirar

sinto que minha doença respiratória escapa ao meu controle

eu não espero nenhuma melhora da minha doença respiratória.

minha doença debilitou-me física e mentalmente, o que faz com que eu precise

da ajuda de alguém 


\section{SEÇÃO 5}

Indica a resposta sim ou não, para definir os efeitos da medicação na doença respiratória:

minha medicação não está me ajudando muito 88,2

fico envergonhado ao tomar medicamentos em público ...........................53,9

minha medicação provoca-me efeitos colaterais desagradáveis...................81,1

minha medicação interfere muito com o meu dia a dia.................................70,3

\section{SEÇÃO 6}

Indica a resposta sim ou não, as atividades que podem ser afetadas pela respiração

levo muito tempo para lavar-me ou vestir-me

74,2

demoro muito tempo ou não consigo tomar banho de chuveiro ou na

banheira.

ando mais devagar que as outras pessoas, ou tenho que parar para descansar

demoro muito tempo para realizar as tarefas como o trabalho da casa, ou tenho que parar para descansar 70,6

quando subo um lance de escadas, vou muito devagar, ou tenho que parar

para descansar

se estou apressado ou caminho mais depressa, tenho que parar para

descansar ou ir mais devagar

por causa da minha respiração, tenho dificuldade para desenvolver atividades

como: subir ladeiras, carregar objetos subindo escadas, dançar, praticar

esporte leve

por causa da minha respiração, tenho dificuldades para desenvolver atividades como: carregar grandes pesos, fazer "cooper" ou

nadar.

por causa da minha respiração, tenho dificuldades para desenvolver atividades como: trabalho manual pesado, correr, andar de bicicleta, nadar rápido ou praticar esportes de

competição.

\section{SEÇÃO 7}

Indica a resposta sim ou não, para outras atividades que geralmente podem ser afetadas pela sua doença respiratória:

praticar esportes ou jogos que impliquem esforço físico 64,8

sair de casa para me divertir $.79,8$

sair de casa para fazer compras. 81,0

fazer o trabalho de casa.... 79,1

sair da cama ou da cadeira

Questão que melhor define a forma como é afetado pela doença respiratória: não me impede de fazer nenhuma das coisas que eu gostaria de fazer. .0 impede-me de fazer uma ou duas coisas que eu gostaria de fazer 42,0 impede-me de fazer a maioria das coisas que eu gostaria de fazer 84,2 impede-me de fazer tudo o que eu gostaria de fazer. 